\title{
The Effect of Low-Temperature Aging on the Microstructure and Deformation of Uranium- 6wt\% Niobium: An In-Situ Neutron Diffraction Study
}

\author{
D.W. Brown ${ }^{1}$, M.A.M. Bourke ${ }^{1}$, A.J. Clarke ${ }^{2}$, R.D. Field ${ }^{1}$, R.E. Hackenberg ${ }^{1}$, W.L. \\ Hults $^{1}$, D.J. Thoma ${ }^{3}$
}

\author{
${ }^{1}$ Material Science and Technology Division, Los Alamos National Laboratory, Los \\ Alamos, NM, 87545 \\ ${ }^{2}$ Department of Metallurgical and Materials Engineering, Colorado School of Mines, \\ 1500 Illinois Street, Golden, CO 80401 \\ ${ }^{3}$ Department of Materials Science and Engineering, University of Wisconsin Madison, \\ Madison WI 53706
}

\begin{abstract}
The mechanical properties of uranium-niobium alloys evolve with aging at relatively low temperatures due to subtle microstructural changes. In-situ neutron diffraction measurements during aging of a monoclinic $\mathrm{U}-6 \mathrm{Nb}$ alloy at temperatures to $573 \mathrm{~K}$ were performed to monitor these changes. Further, in-situ neutron diffraction studies during deformation of $\mathrm{U}-6 \mathrm{Nb}$ in the as-quenched state and after aging for two and eight hours at $473 \mathrm{~K}$ were completed to assess the influence of microstructural evolution on mechanical properties. With heating, large anisotropic changes in lattice parameter were observed followed by relaxation with time at the aging temperature. The lattice parameters return to nearly their initial values with cooling. The active plastic deformation mechanisms including, in order of occurrence, shape-memory de-twinning, mechanical twinning, and slip-mediated deformation do not change with prior aging. However, the resistance to motion of the as-quenched martensitic twin boundaries increases following aging, resulting in the observed increase in initial yield strength.
\end{abstract}


Draft Feb. 2016

\section{Introduction}

The crystal structure of solid pure uranium at high temperature $(1049 \mathrm{~K}<\mathrm{T}<$ $1405 \mathrm{~K}$ ) is body-centered cubic ( $\gamma$ phase) [1]. On cooling, uranium experiences a solidsolid phase transformation to the tetragonal $\beta$ phase followed by a second transformation to an orthorhombic $\alpha$ phase, which is stable at room temperature. To improve the room temperature mechanical properties and corrosion resistance, attempts have been made to alloy uranium with other elemental metals such as Mo [2, 3], $\mathrm{Nb}[4], \mathrm{Zr}[5]$ and $\mathrm{Ti}[6,7]$, each of which is soluble in the high temperature $\gamma$ phase. Although these elements have minimal solubility in the $\beta$ or $\alpha$ phases of uranium, metastable martensitic phases can be formed by moderate to rapid quenching from the high-temperature $\gamma$ phase. The addition of niobium to uranium is of particular interest because it significantly increases the oxidation resistance and increases the ductility [8].

When quenched from high temperatures to prevent diffusional decomposition, the uranium-niobium alloy system has a rich metastable phase diagram [4, 9-13]. At low niobium $([\mathrm{Nb}]<3.5 \mathrm{wt} \%)$ content the metastable alloy has an $\alpha^{\prime}$ orthorhombic structure, similar to pure uranium, with an expanded $\mathbf{b}$ and contracted $\mathbf{a}$ lattice parameter. As niobium content is increased to intermediate values $(3.5 \mathrm{wt} \%<[\mathrm{Nb}]<6.5 \mathrm{wt} \%)$, the alloy assumes an $\alpha^{\prime \prime}$ monoclinic structure that is characterized by an increase of the $\gamma$ angle of the orthorhombic structure. Further niobium enrichment $(6.5 \mathrm{wt} \%<[\mathrm{Nb}]<9$ $\mathrm{wt} \%$ ) yields a tetragonal distortion of the body-centered cubic structure of $\gamma-\mathrm{U}$, termed $\gamma^{\mathrm{o}}$. Finally, above roughly $9 \mathrm{wt} \%$ niobium the bcc $\gamma$ phase is retained to room temperature with quenching. The transformation temperatures between the phases during quenching and heating of alloys with up to $10 \mathrm{wt} \%$ niobium have recently been reported [14], but 
early studies indicated that both the austenitic and martensitic transformations were dependent on heating and/or cooling rate [9]. The lattice parameters of each phase have been determined with $\mathrm{x}$-ray diffraction and reported $[4,10,11]$.

The deformation of $\mathrm{U}-\mathrm{Nb}$ alloys in the $\alpha^{\prime \prime}$ phase field (near $6 \mathrm{wt} \%$ ) have been studied extensively [15-18] because the superior corrosion resistance and ductility of this particular composition leads to use in several applications. In-situ neutron diffraction during deformation to monitor the evolution of crystallographic texture with tensile deformation [18] coupled with ex-situ electron microscopy studies $[19,20]$ have shown that $\mathrm{U}-6 \mathrm{wt} \% \mathrm{Nb}(\mathrm{U}-6 \mathrm{Nb})$ exhibits distinct dominant deformation mechanisms, detwinning of martensitic variants formed during transformation, formation of mechanical twins, and finally slip mediated deformation, with increasing strain.

It is well known that $\mathrm{U}-\mathrm{Nb}$ alloys near $6 \mathrm{wt} \%$ are age hardenable by heat treatments well below the $920 \mathrm{~K}$ monotectoid. Aging at temperature greater than roughly $575 \mathrm{~K}$ results in significant hardening with corresponding loss of ductility and loss of corrosion resistance [8]. The hardening is due to non-lamellar precipitation at early time followed by cellular decomposition of the $\alpha^{\prime \prime}$ toward the equilibrium phases of niobiumpoor $\alpha$ and niobium-rich $\gamma$ phase [8, 9, 21-25] at long times. However, significant hardening is also observed after aging at temperatures as low as $475 \mathrm{~K}[23,26]$, but experimental determination of the mechanism of this low temperature hardening has remained elusive $[23,26]$. Using transmission electron microscopy (TEM), Hsiung interprets the microstructural evolution (at nominally $6 \mathrm{wt} \% \mathrm{Nb}$ ) as being consistent with spinodal decomposition after aging at $473 \mathrm{~K}$ for as little as 16 hours. In contrast, Clarke et al. [23] did not observe statistically relevant chemical heterogeneity (beyond their 
quoted uncertainty of $1 \%$ ) with atom probe tomography at the nm scale after as much as 70 days at $473 \mathrm{~K}$, which is inconsistent with spinodal decomposition. It is worth noting that Clarke et al. did observe significant chemical variations after aging at a higher temperature, $573 \mathrm{~K}$, which is consistent with prior work at this temperature $[8,9,21,22$, $27,28]$. Moreover, a thermodynamics-based argument against spinodal decomposition as a low temperature aging mechanism was presented by Clarke et al. [23].

In order to better understand the microscopic origins of the aging process and the concomitant change in mechanical response, we have carried out in-situ neutron diffraction measurements: (1) during low temperature aging of a U-6Nb alloy at $373 \mathrm{~K}$, $473 \mathrm{~K}, 523 \mathrm{~K}$, and $573 \mathrm{~K}$ for up to 40 hours, and (2) during deformation of U-6Nb in the as-quenched condition as well as after aging at $473 \mathrm{~K}$. As probe particles, neutrons have an advantage over $\mathrm{x}$-rays and electrons in that they penetrate distances on the order of centimeters into most materials, including uranium. This allows the bulk microstructure (as opposed to a surface layer) to be monitored while under non-ambient conditions. Changes in lattice parameters during heating which are large compared to the expected thermal expansion of $\alpha-\mathrm{U}$ are observed, followed by time dependent relaxation of the lattice parameter during subsequent isothermal holds. Moreover, based on the evolution of the texture, we find that, while the initial yield strength of the material increases after low temperature aging ( $473 \mathrm{~K}$ ), the active deformation mechanisms do not change. The motion of transformation twin boundaries, which is responsible for the initial yield phenomenon $[17,18]$ becomes more difficult, but remains the predominant active deformation mode at small strains. However, the current data cannot unambiguously 
Draft Feb. 2016

identify the microscopic mechanism of the increased resistance to motion of the transformation twin boundaries with low temperature aging.

\section{Experimental Details}

\section{A. Sample Preparation}

Two different sources of nominally U-6Nb material were used for the experiments [14]. Niobium concentration-dependence and aging experiments were performed on samples made in small batches specifically intended to yield (compositionally) homogenized samples [14, 29]. Small-scale ( $\sim 50$ gram) U-Nb alloy buttons were synthesized by arc melting high-purity, unalloyed depleted uranium and elemental niobium under an argon partial pressure. The challenges of mixing elements with dissimilar melting points and densities required progressive additions of the $\mathrm{U}$ charge to the $\mathrm{Nb}$, which required about 30 melting steps. After the final melt, a portion of the button was cut off, re-melted, and suction cast into a 5-mm-diameter rod, resulting in rapid quenching to minimize micro-segregation. The rod was then homogenized for 100 hours at $1273 \mathrm{~K}$ under vacuum and water quenched. A total of 41 alloys were made, with nominal compositions separated by $0.25 \mathrm{wt} \%$ increments that spanned $0-10 \mathrm{wt} \% \mathrm{Nb}$. Chemical analyses of the final rods, as determined by direct current plasma emission spectroscopy, are shown in Table 1. Throughout this work, these samples will be referred to as homogenized $\mathrm{U}-6 \mathrm{Nb}[14]$.

For the deformation experiments, samples were machined from plates that were produced in large quantities. Cast uranium and strip niobium were vacuum induction melted and cast in an yttria-coated graphite crucible. The ingot then underwent a double vacuum arc re-melting procedure, in which the ingot was the consumable electrode. The 
double arc-cast ingot was homogenized for 18 hours at $1373 \mathrm{~K}$ in vacuum. Pucks, $64 \mathrm{~mm}$ thick and $190 \mathrm{~mm}$ in diameter, were cut and machined from the homogenized ingot. The pucks were clock rolled under argon at $1123 \mathrm{~K}$ to a final thickness of $9 \mathrm{~mm}$ using $13 \%$ reduction per pass. The pucks were then solutionized at $1123 \mathrm{~K}$ for 4 hours under vacuum, and oil quenched. Because of the larger scale of the production process, chemical inhomogeneity within the specimens persisted in the form of $\mathrm{Nb}$ bands of amplitude 4-8 wt $\% \mathrm{Nb}$, with length scale on the order of 100 microns. Wet chemical analysis of a sample indicated that the final niobium content was actually $5.77 \mathrm{wt} \%$. This pedigree of material has been referred to in the literature as banded $\mathrm{U}-6 \mathrm{Nb}$ [14]. Complete chemical analysis of the banded material can also be found in Table 1.

Pin-holed flat dog-bone tensile samples were machined with a gauge cross section of $6.35 \times 2.5 \mathrm{~mm}$ and gauge length of $50 \mathrm{~mm}$ (ASTM Standard A370-09). Two tensile specimens underwent aging heat treatments at $473 \mathrm{~K}$ for 2 and 8 hours and water quenched, while one was maintained in the solutionized and quenched condition.

\section{B. Neutron Diffraction}

The dependence of the structure and lattice parameters of the $\mathrm{U}-\mathrm{Nb}$ alloy system on the niobium concentration was measured on the Neutron Powder Diffractometer (NPD), while the in-situ accelerated aging and deformation measurements were completed on the Spectrometer for MAterials Research at Temperature and Stress (SMARTS). Both diffractometers are at the Lujan Neutron Scattering Center at LANL. NPD [30] and SMARTS [31] are similar and may be described concurrently. Both diffractometers accept a pulsed white beam (useful range from 0.5 to $4 \AA$ ) of neutrons generated through spallation reactions in a tungsten target and moderated by a water 
moderator at $283 \mathrm{~K}$. SMARTS has a neutron guide along much of the incident flight path, increasing the incident beam flux on the sample by roughly five times, at a small cost in resolution and beam divergence. In both cases, the incident neutron beam is comparable to the size of the sample (or gauge section of the tensile sample), essentially bathing the sample in the neutron beam.

The homogenized $\mathrm{U}-6 \mathrm{Nb}$ samples were placed in the center of either diffractometer, roughly $30 \mathrm{~m}$ from the moderator. Both instruments have detector banks consisting of ${ }^{3} \mathrm{He}$ filled tubes located 1.5 to $2 \mathrm{~m}$ from the sample in the horizontal plane at $\pm 90^{\circ}$ relative to the incident beam. Spectra from individual tubes are summed, with corrections applied for differences in diffraction angle and flight path (time-focused), to provide a single integrated diffraction pattern for each detector bank. Due to the pulsed time structure and continuous energy spectrum of the incident beam, the time-of-flight (TOF) technique can be used to record an entire diffraction pattern in a single detector bank; that is with a co-linear diffraction vectors.

On NPD, diffraction patterns were recorded from 40 samples with niobium concentration between 0.25 and 10 weight percent (wt\%) [29]. The samples were manually placed in the diffractometer with their cylinder axis vertical, which introduces some sample positioning uncertainty that is greater than the statistical uncertainty inherent in the fitting of diffraction patterns.

In-situ aging experiments at $373 \mathrm{~K}, 473 \mathrm{~K}, 523 \mathrm{~K}$ and $573 \mathrm{~K}$ were performed on homogenized U-6Nb material in SMARTS [31] in a vacuum $\left(\sim 10^{-6}\right.$ Torr $)$ furnace heated by tungsten wire meshes above and below the sample position. The furnace temperature was controlled by a thermocouple in close proximity to the sample. A second 
thermocouple in mechanical contact with the sample recorded the sample temperature. The solutionized and quenched samples were heated to the desired aging temperature as quickly as possible without overshooting. Because the radiative coupling between the sample and the furnace is relatively weak (especially at the lowest temperatures studied), the heating time was typically $\sim 30$ minutes at a roughly constant rate. Upon reaching the aging temperature, the sample temperature was held constant to within $\pm 2 \mathrm{~K}$ for the duration of the experiment. A single diffraction pattern of sufficient quality to complete Rietveld refinement of the lattice parameters was achieved with 3 minutes of counting. Patterns were collected continuously for up to 36 hours at temperature. Typically, the count time was increased to 20 minutes after the kinetics of the microstructural evolution retarded ( $\sim 3$ hours).

Data was also collected with $\sim 3$ minute resolution during cooling in the vacuum furnace. A neutron beam loss during the $373 \mathrm{~K}$ aging ended that particular test at roughly 20 hours and no data was collected on cooling. Likewise, the $473 \mathrm{~K}$ aging experiment was interrupted by a beam loss, but this sample was maintained at temperature during the outage and diffraction data was collected during cooling to room temperature.

Room temperature in-situ deformation experiments were completed on banded U$6 \mathrm{Nb}$ alloy samples on the SMARTS diffractometer on solutionized and quenched material, material aged (ex-situ) at $473 \mathrm{~K}$ for two hours and eight hours. The samples were deformed in a horizontal custom built load frame, with the load axis oriented at $45^{\circ}$ relative to the incident beam, such that the detectors on either side of the specimen recorded data with diffraction vectors parallel $(\mathbf{Q} \|)$ and transverse $\left(\mathbf{Q}^{\perp}\right)$, to the applied load simultaneously [31]. An extensometer was used to determine macroscopic 
engineering strain and load measured by a load cell during the deformation tests. A cadmium mask was used to shield the steel knife edges of the extensometer from the incident neutron beam. However, in the case of the sample aged for eight hours at $473 \mathrm{~K}$, the mask was placed too low and the steel (110) peak appears in the diffraction pattern at

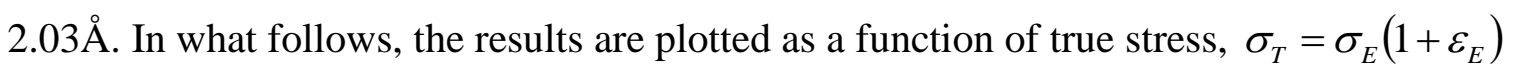
and true strain, $\varepsilon_{T}=\ln \left(\varepsilon_{E}+1\right)$.

\section{Data Analysis}

Rietveld analysis and single peak fitting were completed on the diffraction data using the General Structural Analysis System (GSAS) software package developed at Los Alamos [32]. For the $\alpha^{\prime}$ and $\alpha^{\prime \prime}$ structures, the space group utilized in the analysis was (C $1121 / m)$ with 2 equivalent atom positions, $(x, y, z)$ and $(-x,-y, z+1 / 2)$, each with a multiplicity of 4 . The non-conventional space group facilitated comparison of the low niobium concentration orthorhombic phase with the monoclinic phase at intermediate niobium concentrations, with the transformation being manifested by the deviation of the angle between the $\mathbf{a}$ and $\mathbf{b}$ lattice vectors from $90^{\circ}$. The peak positions of the body centered tetragonal $\gamma_{0}$ phase were calculated from the $\mathrm{P} 4 / \mathrm{n} \mathrm{m} \mathrm{m}$ space group with $\mathrm{a}=$ 4.946 $\mathrm{A}$ and $\mathrm{c}=3.373 \AA$ found for $\mathrm{U}-7 \mathrm{Nb}$ in previous work [33].

To accommodate anisotropic peak broadening, a peak profile function that allowed for variation of the peak width depending on the crystallographic direction was utilized in the Rietveld refinement [34]. The crystallographic texture was modeled by GSAS using an $8^{\text {th }}$ order spherical harmonics expansion of the orientation distribution function. The coefficients of the spherical harmonics are determined by fitting the calculated peak intensities to those observed. In addition to Rietveld refinement, single- 
peak fitting was completed using the Von Dreele, Jorgensen, and Windsor convolution profile function [35] embedded in GSAS.

Rietveld refinement has the advantage that more accurate lattice parameters and texture information are obtained with data of lesser statistical quality because the entire pattern is fit to a constrained structural model. However, the lattice parameters so determined are the result of an "empirical average" over all of the grains and crystal orientations that contribute to the diffraction pattern. In contrast, single peak fits provide the interplanar spacing of a specific set of atomic planes in a family of grains with common orientation with respect to the diffraction vector, and are thus more easily interpreted.

\section{C.1. Inverse Pole Figures}

Whereas pole figures map the density of a single crystallographic plane normal (pole) with respect to sample direction, inverse pole figures (IPF) map the density of all poles (hkl) along a particular sample orientation (e.g. the rolling, transverse, and normal directions of a rolled plate). This particular projection of the orientation distribution function is well suited to TOF diffraction measurements on a white neutron beam since the intensities (directly related to pole density) of many diffraction peaks (31 in this case) are determined with collinear diffraction vectors, that is along a single sample direction. Rietveld analysis, in particular, is key to the IPF determination, as the crystal-model based fit allows for accurate determination of pole density of orientations with significantly overlapped diffraction peaks. Thus, a single measurement on SMARTS, consisting of two diffraction patterns with orthogonal diffraction vectors, directly and 
simultaneously measures two distinct IPF's along orthogonal directions, parallel and transverse to the straining direction.

\section{2 Lattice Strains}

Diffraction inherently selects grains with common crystal plane normals (poles) parallel to the diffraction vector (defined by the instrument geometry) and differentiates these based on interplanar (d-) spacing. For example, grains with their (110) poles parallel to the diffraction vector (and loading axis), so called (110) oriented grains, contribute uniquely to the diffraction peak at $d=2.56 \AA$ and said peak comprises an average response of this subset or family of grains. The change in the interplanar spacing along the different crystallographic directions as a function of applied stress, $d^{h k l}(\sigma)$,

represents elastic lattice strains,

$$
\varepsilon_{\text {lat }}^{h k l}(\sigma)=\frac{d^{h k l}(\sigma)-d_{0}^{h k l}}{d_{0}^{h k l}}, \text { where } d_{0}^{h k l} \text { represents a }
$$

reference interplanar spacing for the given crystallographic plane. A similar equation can be written with reference to the change in the individual lattice parameters, $\mathbf{a}, \mathbf{b}, \mathbf{c}$. The statistical uncertainty associated with the Rietveld refinement of the lattice parameters is very small in all cases, typically on the order of $5 \times 10^{-5}$ or less. In contrast, the uncertainty associated with single peak fits might be as high as $20 \times 10^{-5}$, in particular for broad peaks such as those from U-6Nb. These should be taken as relative uncertainties (or strain uncertainties) as absolute uncertainty is highly dependent on instrument calibration procedures and is, in all cases, significantly larger.

\section{Experimental Results}

\section{A. Dependence on [Nb]}


Neutron diffraction patterns from homogenized U-Nb samples with several different niobium concentrations are shown in figure 1. Each structure in the uraniumrich side of the phase diagram is represented. At the lowest niobium concentration studied, $0.25 \mathrm{wt} \%$, the alloy is $\alpha^{\prime}$ (orthorhombic). At a niobium concentration of $2.0 \mathrm{wt} \%$, the crystallographic structure is still orthorhombic, but the peaks have shifted significantly and are considerably broader. The alloy is well into the $\alpha^{\prime \prime}$ (monoclinic) phase field at a niobium concentration of $6 \mathrm{wt} \%$ and again, the peaks are very broad. Diffraction peaks indicative of both the $\alpha^{\prime \prime}$ and $\gamma^{\circ}$ (tetragonal) phases are observed in the $6.5 \mathrm{wt} \%$ alloy. At $7 \mathrm{wt} \%$ niobium, the diffraction peaks are once again sharp and the alloy is fully within the $\gamma^{\mathrm{o}}$ phase field. Finally, the high temperature body centered cubic phase, $\gamma$, is maintained to room temperature at a $10 \mathrm{wt} \%$ niobium concentration.

Figure 2 shows the behavior of the lattice parameters $\left(\mathbf{a}, \mathbf{b}, \mathbf{c}\right.$ and $\gamma$ ) of the $\alpha^{\prime}$ and $\alpha^{\prime \prime}$ phases as a function of niobium content up to $6.25 \mathrm{wt} \%$. The a lattice parameter increases with increasing niobium content while $\mathbf{b}$ decreases. Also, the $\mathbf{c}$ parameter increases weakly initially, but begins to decrease above $5 \mathrm{wt} \%$. These trends are consistent with those published by Jackson [10] and Anagnostidis et al. [4], but differ from those reported by Tangri et al. [11]. Jackson [10] rationalized the behavior of the lattice parameters with increasing niobium content through a simple argument based on the relative sizes of the niobium and (highly anisotropic) uranium atoms. The rates of change of the $\alpha^{\prime \prime}$ lattice parameters $(\mathbf{a}, \mathbf{b}, \mathbf{c}$ and $\gamma)$ with $[\mathrm{Nb}]$ near 6 wt\% in both an absolute and relative sense are shown in table 2 . The a and $\gamma$ parameters are the most sensitive to the niobium concentration, changing by 1 to $2 \%$ per unit change in $[\mathrm{Nb}]$. The c lattice parameter is relative insensitive to $[\mathrm{Nb}]$ near $6 \mathrm{wt} \%$. 
Diffraction patterns were also collected from homogenized U-Nb alloy samples with $[\mathrm{Nb}]$ from $6.5-10 \mathrm{wt} \%$ in the $\gamma_{0}$ and $\gamma$ phase. Though not reported fully here, it is worthwhile noting the lattice parameters of the $\gamma_{0}$ at the phase boundary of nominally U$6.5 \% \mathrm{Nb}$, are $\mathrm{a}_{\gamma 0}=4.935 \AA$ and $\mathrm{c}_{\gamma 0}=3.365 \AA$. These can be transformed into the $\alpha^{\prime \prime}$ coordinate system to calculate corresponding values of $\mathrm{a} \alpha^{\prime \prime}, \mathrm{b} \alpha^{\prime \prime}, \mathrm{c}_{\alpha^{\prime \prime}}$, and the monoclinic angle, $\gamma,[36]$ as $2.986 \AA, 5.618 \AA, 4.935 \AA$ and $98.22^{\circ}$. At $6.25 \mathrm{wt} \% \mathrm{Nb}$, the highest [Nb] shown in figure 2, the $\alpha^{\prime \prime}$ lattice parameters are $2.914 \AA$, $5.718 \AA$, $4.965 \AA$ and $93.26^{\circ}$. When compared to the evolution of lattice parameters with [Nb], it is clear that while the c lattice parameter changes little across the phase boundary, there is a discontinuous change in the $\mathrm{a}, \mathrm{b}$ and $\gamma$ lattice parameters across the boundary. Carpenter et al. [36] reported a similar discontinuous change when the phase transformation was driven in the reverse direction from $\gamma_{0}$ to $\alpha^{\prime \prime}$ through application of stress.

\section{B. Isothermal aging}

Figure 3 shows diffraction patterns from homogenized $\mathrm{U}-6 \mathrm{Nb}$ material, immediately after reaching $473 \mathrm{~K}, 36$ hours after reaching $473 \mathrm{~K}$, and at room temperature after completion of the aging experiment. The diffraction patterns collected at elevated temperature have been offset from the other two for ease of comparison of the common temperature data. The first pattern collected at $473 \mathrm{~K}$ has relatively poor statistics because it was expected that the kinetics would be relatively fast immediately upon reaching temperature, so the integration time was short ( $\sim 3$ minutes) to optimize time resolution. The diffraction patterns have all been normalized to the integrated beam current during the individual runs, but are otherwise raw data. Clearly the diffraction pattern evolves strongly during the heating. The $(\overline{1} 11)$ and $(\overline{1} 10)$ peaks shift 
significantly to higher d-spacing; the (110) shifts to a lesser degree to lower d-spacing. Continued evolution of the diffraction pattern is evident with extended time at temperature. In general, the peaks relax back toward their room temperature positions. Surprisingly, following cooling to room temperature, the diffraction pattern is indistinguishable from the initial room temperature diffraction pattern. The data were plotted in this way specifically to highlight the similarity between the room temperature diffraction patterns before and after 36 hours at $473 \mathrm{~K}$.

Figure $4 \mathrm{a}$ shows the room temperature diffraction pattern from homogenized U$6 \mathrm{Nb}$ prior to heating. Figures 4b-d show (b) the initial pattern upon reaching $573 \mathrm{~K}$, (c) after 1 hour and (d) after 35 hours at $573 \mathrm{~K}$, respectively. Upon reaching $573 \mathrm{~K}$, the material has transformed to the $\gamma_{0}$ phase. After an hour, the diffraction pattern is impossible to analyze quantitatively, but it appears that the material has reversed the transformation toward a two-phase $\alpha^{\prime \prime}$ and $\gamma_{0}$ microstructure. After 35 hours, the diffraction pattern has continued to evolve, apparently towards the $\alpha^{\prime \prime}$ structure, but again quantitative analysis is not possible.

Figures 5a-d show the evolution of the lattice parameters $\mathbf{a}, \mathbf{b}, \mathbf{c}$, and $\gamma$ of $\mathrm{U}-6 \mathrm{Nb}$ as a function of time at temperature following heating to a specified temperature ( $373 \mathrm{~K}$, $473 \mathrm{~K}$, and $523 \mathrm{~K}$ ). Time zero is taken as the point at which the aging temperature is reached. The axes on the right of the plots show the fractional change in $\mathbf{a}, \mathbf{b}$, and $\mathbf{c}$ (the "lattice strain"), referenced to the value at room temperature prior to heating. The scales on plots a-c all represent $2.5 \%$ strain full scale. Like the sample heated to $573 \mathrm{~K}$, the sample heated to $523 \mathrm{~K}$ partially transformed to $\gamma_{0}$ upon reaching the aging temperature, but was recognizably $\alpha^{\prime \prime}$ within 10 minutes after reaching the target temperature. Thus, 
the lattice evolution for this sample is shown starting 10 minutes after reaching temperature.

The initial changes in the lattice parameters of the homogenized U-6Nb with heating (over roughly 30 minutes) are strongly orientation dependent. The a lattice parameter increases dramatically with increasing temperature ( $>2 \%$ with $\Delta \mathrm{T} \sim 170 \mathrm{~K})$, while the $\mathbf{b}$ parameter decreases by roughly half that. The change in the $\mathbf{c}$ parameter is nearly within uncertainty of zero. The monoclinic angle, $\gamma$, increases strongly with increasing temperature. If the changes in lattice parameter are interpreted as thermal expansion, orientation dependent coefficients of thermal expansion may be determined and are shown in table 3 , along with those of $\alpha$ uranium for comparison; they differ greatly. The thermal expansion coefficient of randomly textured $\mathrm{U}-6 \mathrm{Nb}$ is $14.5 \times 10^{-6} / \mathrm{K}$ $[14,37]$, similar to that of $\alpha$ uranium, $13.9 \times 10^{-6} / \mathrm{K}[38]$.

After the aging temperature is reached and the sample temperature is held constant, the lattice parameters evolve in the opposite direction (relax) relative to heating. The relaxation rate is temperature dependent; little relaxation is observed during the hold at $373 \mathrm{~K}$, while the most rapid initial relaxation is observed at $523 \mathrm{~K}$. With long times at temperature, the lattice parameters approach steady state values that are relatively independent of the aging temperature. The a lattice parameter decreases by more than $1 \%$ with 40 hours at $473 \mathrm{~K}$ and, regardless of temperature, approaches $2.923 \AA$ at long times. The $\mathbf{b}$ lattice parameter increases with time at temperature such that by the end of the aging, the lattice parameter is nearly the same as the initial value at room temperature. The monoclinic angle decreases with time, asymptotically approaching $93.3^{\circ}$, roughly independent of the temperature. 
With subsequent cooling to room temperature, much, if not all, of the lattice parameter evolution during the hold at temperature is recovered. That is, the final lattice parameters at room temperature after aging are similar to the fresh material, within $0.2 \%$. After cooling from aging at $473 \mathrm{~K}$ to room temperature, the changes in the $\mathbf{a}, \mathbf{b}, \mathbf{c}$, and $\gamma$ lattice parameters relative to the as-quenched values are $0.07 \%,-0.04 \%,-0.1 \%$, and $0.08^{\circ}$ where uncertainties are typically roughly $0.02 \%$. Likewise, after cooling from $523 \mathrm{~K}$ where partial transformation to the $\gamma_{0}$-phase was observed on initial heating, the changes in the lattice parameters were $-0.1 \%,-0.006 \%,-0.2 \%$, and $-0.01^{\circ}$ at room temperature. Once again, effective orientation dependent CTE's can be calculated from cooling and are also shown in table 3. The CTE's on cooling are much closer to, although still distinct from, $\alpha$-uranium.

Figure 6 shows the evolution of the fractional change in interplanar spacing of the $(\overline{1} 10),(110)$ and $(\overline{1} 11)$ planes, as well as the $(002) /(021)$ doublet during aging at 473 K. In order to compare with the Rietveld results, the same values were calculated using the $\mathbf{a}, \mathbf{b}, \mathbf{c}$ and $\gamma$ lattice parameters. The single orientation (hkl) responses are well reproduced by the calculation based on the evolution of the lattice parameters. Interestingly, the $(002) /(021)$ doublet is also well captured by the average response of the two orientations calculated from the lattice parameters. This provides confidence in the interpretation of the results from the Rietveld refinement. Moreover, it provides an example of an even larger lattice strain response to the initial heating compared to that observed in the lattice parameters, with the $(\overline{1} 10)$ and $(\overline{1} 11)$ interplanar spacings increasing by more than $3 \%$ and $2.5 \%$, respectively, when heated from room temperature to $473 \mathrm{~K}(\Delta \mathrm{T} \sim 170 \mathrm{~K})$. Again, the lattice strain relaxes with time at temperature and, like 
the lattice parameters, return to within $\sim 0.1 \%$ of their initial values when returned to room temperature.

While not shown for brevity, the peak breadths were also tracked during the aging heat treatment. The initial full width at half maximum $(\Delta \mathrm{d} / \mathrm{d})$ of the $(\overline{1} 10),(110)$ and ( 111$)$ peaks are initially between $1 \%$ and $2 \%$ and do not change during the $473 \mathrm{~K}$ aging heat treatment outside of the uncertainty of $0.1 \%$ or less (depending on (hkl)).

\section{Effect of Aging on Mechanical Properties}

Figure 7 shows diffraction patterns collected at room temperature from the three tensile specimens made from banded U-6Nb material (offset for clarity): as-quenched and after 2 hours or 8 hours at $473 \mathrm{~K}$. Based on the results shown in Fig. 5, it is unsurprising that other than a small peak at $2.03 \AA$ from the steel blade of the extensometer in the 8 hour aged sample, the diffraction patterns are nearly identical. Lattice parameters determined from Rietveld refinement of the patterns are within the uncertainty that results from slight misalignment of the distinct samples in the load frame.

Figure 8 shows the stress-strain curves obtained from the three materials with different aging treatments. The dips in the stress-strain curves are due to relaxation while the test is interrupted to allow time to collect neutron diffraction data of sufficient statistical quality. The unloading data is not shown for the case of the as-quenched and 8 hour aged material because it obscures the figure without adding any new information. While it is clear that the initial yield point increases with aging at $473 \mathrm{~K}$, accurate yield points are difficult to discern because the initial loading is never truly linear. However, taking the previously reported elastic modulus of $62 \mathrm{GPa}$ [17], $0.2 \%$ offset yield strengths 
are determined roughly to be $110 \mathrm{MPa}$ for the as-quenched material, $350 \mathrm{MPa}$ for the 2 hour aged material, and $440 \mathrm{MPa}$ for the 8 hour aged material.

As is typical in $\mathrm{U}-6 \mathrm{Nb}$, the initial yield point and region of reduced hardening rate is followed by increased hardening and a secondary yield point regardless of aging heat treatment. The secondary yield point (roughly marked by dashed lines) is chosen qualitatively as the point where the hardening rate is decreasing the most rapidly, at a strain of roughly 0.06 . So defined, the secondary yield point occurred at stresses of 700 $\mathrm{MPa}$ in the as-quenched material, $730 \mathrm{MPa}$ in the 2 hour aged material and $780 \mathrm{MPa}$ in the 8 hour aged material. In contrast to the primary yield point, the dependence of the secondary yield point on aging is relatively small, occurring over a stress range of $\sim 80$ MPa. The difference in flow stress is roughly maintained throughout the remainder of the test. The current results show less age hardening associated with the secondary yield point than previously observed in low temperature aged material [23].

Figure 9 shows inverse pole figures parallel to the straining direction from the asquenched and age heat treated materials at the start of the tensile test and after true strains of roughly $0.04,0.08$, and 0.12 . Figure 10 shows the development of the (130) and (130) pole densities, which effectively characterize the evolving texture, as a function of strain during tensile deformation of the as-quenched, 2 hour and 8 hour age heat treated materials. The initial yield points determined from figure 8 are represented by the dotted lines. The secondary yield point occurs at a strain of roughly 0.06 . Prior to deformation, the texture of the material nearly random, regardless of heat treatment. The evolution of the texture with strain is relatively independent of the aging, with the as-quenched material exhibiting slightly stronger textures at the extreme points. In contrast, figure 11 
shows the evolution of the same texture components as a function applied stress. Again, the dotted lines indicate the initial yield point defined for each material age in figure 8 . The stress at which the initial increase of the (130) pole density occurs (100-500 MPa) depends strongly on the aging conditions and corresponds with the macroscopic initial yield strength. The secondary yield points occur between $700 \mathrm{MPa}$ and $800 \mathrm{MPa}$ and roughly correspond to the maxima in the $(\overline{1} 30)$ pole density.

\section{Discussion}

To summarize the observations and ease the discussion, the stresses and strains at which various macroscopic phenomenon (e.g. primary yield) and diffraction effects (e.g. increase in (130) pole density) were observed are listed in table 4. Clearly, low temperature aging (i.e. at $473 \mathrm{~K}$ ) has a pronounced effect on the mechanical response of $\mathrm{U}-6 \mathrm{Nb}$, as well as the underlying micro-mechanics of the deformation. In as-quenched U$6 \mathrm{Nb}$, the immediate increase of (130) pole density with strain (figure 10) parallel to the straining direction is due to preferential selection of specific martensitic variants that best accommodate the imposed deformation by motion of existing transformation twin boundaries (de-twinning) $[17,19,39]$. The point at which the (130) pole density reaches its maximum, at $\sim 0.04$ strain, marks the crossover from de-twinning to secondary mechanical twinning [18], manifested by a discrete re-orientation from the (130) to (130) orientation, and corresponds roughly to the point where the macroscopic

hardening rate, $\mathrm{d} \sigma / \mathrm{d} \varepsilon$, goes from increasing to decreasing. Subsequently, a strong $(\overline{1} 30)$ texture component develops, reaching a maximum at $\sim 0.09$ strain, corresponding roughly to the second increase in macroscopic hardening rate. Finally, continuous rotation of the 
texture component towards an (010) orientation, evident in the IPF's, signals the onset of dislocation mediated deformation at larger strains [18], appearing in figure 10 as a decrease in the $(\overline{1} 30)$ pole density beyond roughly 0.09 strain.

The evolution of texture, which is indicative of the active deformation mechanisms, is nearly independent of the aging condition, meaning that the mechanisms that accommodate the enforced deformation do not change with the aging heat treatment. However, the stress necessary to initiate the deformation mechanism does change with aging heat treatment. In particular the motion of the pre-existing transformation twin boundaries, which is the dominant active deformation mechanism at small strains, becomes more difficult following the aging heat treatments. The initiation of de-twinning occurs at roughly $110 \mathrm{MPa}$ in fresh material, $350 \mathrm{MPa}$ in the two hour aged material, and $440 \mathrm{MPa}$ in the 8 hour aged material. In contrast, the crossover from de-twinning to the secondary twin, marked by the decrease in (130) pole density is only weakly dependent on the length of the aging heat treatment, occurring between 550-650 MPa. Moreover, the cessation of secondary twinning and activation of slip systems, indicated by the subsequent decrease in the $(\overline{1} 30)$ pole density, is also only weakly dependent on the length of the aging heat treatment.

Thus, we conclude that while the active deformation mechanisms remain unaffected by aging, the initial yield point is increased because motion of the twin boundaries that form during quenching through the martensitic transformation requires an increased driving stress following aging. In contrast, the onset of secondary twinning and, subsequently, dislocation mediated plasticity are relatively unaffected by low temperature aging. 
It is clear from the in-situ neutron diffraction data that the microstructure evolves during aging at $473 \mathrm{~K}$. With initial heating, there is a pronounced transient response observed in lattice parameter that relaxes with time at temperature before fully recovering to pre-aging values when the sample is returned to room temperature. The large changes in lattice parameter with initial heating are not consistent with the thermal expansion of pure $\alpha-\mathrm{U}$ and, moreover, are a transient response. Large, strongly anisotropic thermal expansion has been reported in other martensites that exhibit the shape memory effect [40], but no attempt was made to understand the source of the observation.

The aging temperatures discussed in this work ( $373 \mathrm{~K}, 473 \mathrm{~K}, 523 \mathrm{~K}$ and $573 \mathrm{~K})$ are very near the austenitic transformation temperatures determined for this alloy. Hackenberg et al. report $A_{s}$ and $A_{f}$ temperatures of $444 \mathrm{~K}$ and $485 \mathrm{~K}$, respectively, for $\mathrm{U}$ $5.75 \mathrm{Nb}$ when heated at $\sim 50 \mathrm{~K} / \mathrm{sec}$ [14]. These transition temperatures, in particular the $\mathrm{A}_{\mathrm{s}}$ temperature, are somewhat higher than those reported by Vandermeer [9] who also showed that $\mathrm{A}_{\mathrm{s}}$ increases with decreased heating rate. In the present work, we directly observe at least partial transition to the $\gamma_{0}$ phase when heating in-situ to $523 \mathrm{~K}$ and $573 \mathrm{~K}$, but not $373 \mathrm{~K}$ or $473 \mathrm{~K}$ at much slower rates, $\sim 0.1 \mathrm{~K} / \mathrm{sec}$. However, it is clear that the low temperature aging reported herein is near the austenite transition.

The large changes observed in the U-6Nb lattice parameters as the material is heated toward the austenite phase boundary are in the direction that is required by the structural phase transformation (i.e. $\alpha "$ "> $\gamma_{0}$ ) and are roughly the same magnitude. Carpenter et al. [36] reported a $2.1 \%$ decrease in the a lattice parameter, $3.4 \%$ increase in the b lattice parameter, and $3.7 \%$ decrease in the monoclinic angle $(\gamma)$ relative to the equivalent spacings in the $\gamma_{0}$ phase when the phase transformation was driven from the $\gamma_{0}$ 
phase to the $\alpha^{\prime \prime}$ phase by the application of stress. In this work, we observe a $2.5 \%$ increase in $\mathbf{a}, 1.7 \%$ decrease in $\mathbf{b}$, and $5.0 \%$ increase in the monoclinic angle when crossing the boundary from $\alpha^{\prime \prime}$ to $\gamma_{0}$ (i.e. the opposite direction from [36]) by increasing $[\mathrm{Nb}]$. For comparison, when heating from $\alpha^{\prime \prime}$ toward the $\gamma_{0}$ phase, we observe a $2 \%$ increase in $\mathbf{a}, 1 \%$ decrease in $\mathbf{b}$ and $3 \%$ increase in monoclinic angle. Thus, it appears as if the martensitic structure is "anticipating" the transformation to austenite as the transformation temperature is approached.

Based on the changes in lattice parameter across the phase boundary at room temperature with increasing niobium concentration, the transformation strains $\left(\alpha^{\prime \prime}\right.$ to $\left.\gamma_{0}\right)$ along any given crystal orientation have been calculated and are shown in figure 12a on the irreducible stereograph of the monoclinic structure. The dots represent the 31 distinct crystal orientations (hkl) at which the transformation strain was calculated to draw the contours (the same as the peaks included in the Rietveld refinement). As figure 6 demonstrates, the lattice parameter $(\mathbf{a}, \mathbf{b}, \mathbf{c}$, and $\gamma)$ changes observed during heating can be used to calculate the thermal strains at those same crystal orientations. Figures $12 \mathrm{~b}$ and c show the thermal strains observed at the first time interval upon heating to $473 \mathrm{~K}$ and $373 \mathrm{~K}$ for the aging heat treatments, respectively. Both show the same trend over the stereograph as the transformation strains, supporting the idea that the lattice parameters are responding to move the structure toward the austenite phase, prior to reaching the transformation temperature. It is worth noting that the thermal strains can be calculated using the orientation dependent CTE of orthorhombic uranium and, after increasing temperature by $200 \mathrm{~K}$, the strains would be less than the single $0.5 \%$ contour interval on the scale of figure 12 . 
The relaxation of the lattice parameters with time at temperature is very large, $>1 \%$, but could potentially be related to mechanical relaxation of internal stresses. In-situ diffraction studies have reported elastic lattice strains of this order during deformation of $\mathrm{U}-6 \mathrm{Nb}[17,18]$ and even larger during stress induced phase transformation of $\gamma_{0} \mathrm{U}-7 \mathrm{Nb}$ to $\alpha^{\prime \prime}[33]$.

It is important to recall that a single diffraction peak comprises the response of many grains (in this case, martensite orientation variants) sharing a common orientation defined by a specific plane normal (hkl) parallel to the diffraction vector. While each individual grain sits in a unique neighborhood, the diffraction peak can be considered to represent the response of a single grain/variant in an average neighborhood, termed a Homogenous Equivalent Medium (HEM) in the parlance of self-consistent polycrystalline plasticity models $[41,42]$. The HEM necessarily has the thermal (expansion) and elastic (stiffness) properties of the bulk material.

With this in mind, the observed data suggests the following. With increasing temperature approaching the austenite transformation regime, the lattice parameters evolve strongly and anisotropically in anticipation of the transformation; the effective CTE along the $(\overline{1} 10)$ plane normal is over $170 \times 10^{-6} / \mathrm{K}$. Randomly textured U-6Nb has a macroscopic CTE of $\sim 14.6 \times 10^{-6} / \mathrm{K}[14,37]$ at room temperature. Large intergranular/intervariant stresses develop due to the constraint of the neighborhood. For example, Clarke et al. [39] reported the presence of some intergranular tensile accommodation strains after deformation in compression, even though negative accommodation strains were determined for the majority of the martensite variants within the grain. With time at temperature, these stresses relax. 
The response of the grains/variants is phenomenologically analogous to a "stress relaxation" test [43-45], in which a macroscopic increment of displacement is imparted to the boundaries of a mechanical test specimen, resulting in a corresponding instantaneous increase in stress. Subsequently, the crosshead displacement is held constant and the decrease in stress on the sample is monitored with time. Empirically, the time dependence of the stress decrease follows the form $\Delta \sigma=\sigma(t)-\sigma_{0}=\frac{-k T}{V} \log \left(1+\frac{t}{\tau}\right)$ (sometimes called the Feltham equation) where $V$ represents an activation volume, $\tau$ is a characteristic relaxation time, $k$ is the Boltzmann constant and $T$ the temperature [44-46].

In the analogy with the U-6Nb grain/variant in a polycrystalline matrix, the incremental displacement of the grain is provided by the large directional thermal expansion of the grain relative to the isotropic surrounding HEM. Subsequently, as the temperature (displacement) is held fixed, the stress relaxes in the grain and the HEM plays the constraining role of the fixed loading machine. The stress on the grain is necessarily proportional (in a tensor sense) to the elastic portion of the strain which is observed by diffraction, $\sigma_{i j}=C_{i j k l} \varepsilon_{k l}$ where $C_{i j k l}$ represents the single crystal stiffness tensor. For the purposes of this rough analogy, we will simply consider a scalar approximation of Hooke's Law, $\sigma=E_{h k l} \varepsilon$, where $E_{h k l}$ is the effective elastic modulus along the specific crystal direction. With this simplification, the Feltham equation can then be written as $\Delta \varepsilon_{h k l}=\frac{-k T}{V E_{h k l}} \log \left(1+\frac{t}{\tau}\right)$ and related directly to the elastic strains observed by diffraction while holding at temperature.

Figure 13a shows the relaxation of the elastic strains $(-|\Delta \varepsilon|)$ after heating to $473 \mathrm{~K}$ determined from the lattice parameters, $\mathbf{a}, \mathbf{b}, \mathbf{c}$, and $\gamma$ (shear strain calculated from the 
change in the monoclinic angle) fit to the Feltham equation. Figure 13b shows the same for specific crystallographic orientations, $(\overline{1} 10),(110)$, and $(\overline{1} 11)$. The fits are excellent. The characteristic times, $\tau$, derived from the fits are dependent on the orientation, but are on the order of minutes. Likewise, the activation volumes, $V$, are on the order $13000 \AA^{3}$, corresponding a length of $\sim 20 \AA$, or of order 5 unit cells.

It must be stressed that this is a simplistic analogy. The stress relaxation test is defined as uniaxial, while the distortion and constraint on a grain in a polycrystal is inherently triaxial. Moreover, the "displacement" is not held fixed as the grain/variant and surrounding neighborhood relax. The evolution of the strain with time can be fit nearly as well with a power law, i.e. corresponding to a creep test. However, given the simplicity of the analogy, the derived results are reasonable and provide confidence in the rationalization of the observations.

Following low temperature aging, the initial yield stress of the banded $\mathrm{U}-6 \mathrm{Nb}$ is observed to increase due to the increased resistance to motion of the transformation twin boundaries formed during the quench to room temperature (Fig. 11). Clarke et al. [23] speculated that this might be due to rearrangement of transformation twin/lath interfacial structures into lower energy configurations by viscous glide, climb, or ledge/step migration. The thermoelastic martensite structure formed during a rapid quench from the solutionizing temperature of $1073 \mathrm{~K}$ consists of multiple variants with twin and near-twin orientation relationships between them [20]. Defects within these interfaces (likely complexes of transformation dislocations, ledges, step, and disconnections [47]) are necessarily mobile in order to both effect the initial transformation and allow relatively easy interface migration (“de-twinning") during shape memory deformation. However, 
these interfacial defects are not likely to be in their lowest energy configurations due to the rapid quench. Low temperature aging provides both additional energy in the form of the elevated temperature and a strong driver in the form of large intervariant stresses for rearrangement of the variant interfaces to lower energy, less mobile states, with concomitant increased resistance to motion, resulting in the increased initial yield stress. These interfacial rearrangements would also be expected to partially stabilize the martensite structure, resulting in the observed increases in $A_{s}$ and $A_{f}$ temperatures with low temperature aging [9] and reverse transformation during aging at $523 \mathrm{~K}$ and $573 \mathrm{~K}$ observed in this work.

The authors are not aware of any previous proposal of such a mechanism for aging in a SME system. The current diffraction data is unable to provide validation of this speculation as it is unlikely that such local rearrangements would produce an easily recognizable signature in the diffraction measurement which averages over cubic millimeters. However, the current results are consistent with the proposed aging mechanism, thus providing some support. A combination of modeling, using methods such as those in $[47,48]$, and high resolution TEM would be required to address this hypothesis. This would be a challenging undertaking, given the complexity of the crystallography for the martensitic transformation in this system and the high atomic number of uranium which makes high resolution TEM particularly difficult.

While the current data cannot provide direct proof of the age hardening mechanism, it can be used to exclude other potential low temperature aging mechanisms. The slow evolution of the lattice parameter with time was originally suggested to be associated with a decrease in niobium concentration [14] by phase separation, as is 
unambiguously observed in higher temperature aging [8, 9, 21-25]. However, this was later realized to be implausible, as the lattice parameters return to their original room temperature values upon cooling to room temperature, to within $0.2 \%$. Atom probe tomography after low temperature aging at $473 \mathrm{~K}$ also did not reveal significant compositional variations indicative of phase separation [23]. Indeed, the actual relative changes observed in the lattice parameter are not consistent with changes in niobium concentration, as the largest change in lattice parameter observed at room temperature before and after the aging heat treatment is in the $\mathbf{c}$ parameter, which is almost independent of niobium concentration (see Fig. 2c). From figure 2, it is apparent that near 6 weight percent niobium, the $\mathbf{a}$ and $\gamma$ parameters are most sensitive to changes in niobium concentration. The largest observed change in the a parameter, $-0.1 \%$, after aging at $523 \mathrm{~K}$ would correspond to a decrease of $\sim 0.1$ weight percent of niobium. Likewise, the largest change in $\gamma$ angle of $0.08^{\circ}$ after aging at $473 \mathrm{~K}$ corresponds to a decrease of less than 0.05 weight percent niobium. These could be taken as upper limits to the amount of phase decomposition observed during the aging heat treatment.

Another potential low temperature aging mechanism is spinodal decomposition of the U-Nb alloy [26]. Periodic modulation of the niobium content on nanometer length scales associated with spinodal decomposition would not necessarily result in a change in the bulk averaged lattice parameter, but rather an increase in peak breadth corresponding to the distribution of niobium concentration. Given the uncertainty in the measurement of the peak FWHM, roughly $0.1 \%$, the measurement should be sensitive to a similar distribution of lattice parameters, which corresponds to amplitude in the modulation of the niobium content of roughly 0.2 weight percent. In other words, the observed lack of 
peak broadening puts an upper bound on niobium content modulation due to spinodal decomposition of 0.2 weight percent.

\section{Conclusions}

In-situ neutron diffraction measurements during and aging heat treatment and deformation of $473 \mathrm{~K}$ aged nominally $\mathrm{U}-6 \mathrm{Nb}$ materials were completed in an attempt to understand the microstructural origin of the reported increased strength of material following aging heat treatments. At the initial low-stress yield point of $\mathrm{U}-6 \mathrm{Nb}$, strain is accommodated by preferential selection of specific martensitic variants through motion of transformation twins formed during quenching through the martensitic transformation [17] [19, 39]. An increased driving stress to move the twin boundaries is responsible for the observed increased flow stress.

Unfortunately, the diffraction measurements completed in-situ during low temperature aging do not provide a clear cause for the increase resistance to motion of the twin boundaries. With initial heating, large anisotropic transient changes in the monoclinic lattice parameters are observed, followed by subsequent relaxation with time at constant temperature. The response is well described by considering the martensite variant microstructure as individual anisotropic "grains" in an isotropic effect medium. With heating, the grains expand/contract depending on crystal orientation against the constraint of the surrounding medium setting up a large stress, which relaxes with time. The observed relaxation of the elastic lattice strains is well fit by the Feltham equation, which has been developed to fit stress relaxation tests $[44,49,50]$.

Upon return to room temperature, the lattice parameters return to their pre-aging values. Virtually no change in the diffraction pattern is observed when comparing before 
Draft Feb. 2016

and after aging. This result is consistent with a previous suggestion of strengthening due to rearrangement of twin interface structure during aging [23], but cannot provide direct evidence, as it would not present an unambiguous signature in the diffraction data. The current neutron diffraction data can exclude other possible aging mechanisms, such as phase separation by either nucleation and growth or spinodal decomposition, which should be manifested by easily observable permanent changes in the lattice parameters and/or peak breadths, which are unambiguously not observed.

\section{Acknowledgments}

This work has benefited from the use of the Lujan Neutron Scattering Center at LANSCE, which was funded by the Office of Basic Energy Sciences (DOE). Los Alamos National Laboratory is operated by Los Alamos National Security LLC under DOE Contract DE-AC52-06NA25396. 
Draft Feb. 2016

Tables

\begin{tabular}{ccccccccc}
\hline & $\mathrm{Nb}$ & $\mathrm{C}$ & $\mathrm{Cu}$ & $\mathrm{Fe}$ & $\mathrm{Al}$ & $\mathrm{Si}$ & $\mathrm{Mo}$ & $\mathrm{Ti}$ \\
\hline Homogenized Material & 6.04 & 0.0002 & $5 \mathrm{E}-5$ & 0.0004 & $1 \mathrm{e}-5$ & 0.0003 & $3 \mathrm{E}-5$ & $1 \mathrm{E}-5$ \\
\hline Banded Material & 5.77 & 0.020 & 0.0044 & 0.029 & 0.003 & 0.026 & 0.0048 & 0.0016 \\
\hline
\end{tabular}

Table 1. Sample impurity concentrations in wt $\%$.

\begin{tabular}{|l|l|l|l|l|}
\hline & a & b & c & $\gamma$ \\
\hline Units of $\AA / \mathrm{wt} \% \mathrm{Nb}$ & 0.029 & -0.037 & -0.018 & $1.8^{\circ}$ \\
\hline Units of $\% / \mathrm{wt} \% \mathrm{Nb}$ & 1.0 & -0.6 & -0.3 & 2 \\
\hline
\end{tabular}

Table 2. Rate of change of the $\alpha^{\prime \prime}$ lattice parameters with change in $\mathrm{Nb}$ concentration near $6 \mathrm{wt} \% \mathrm{Nb}$ in absolute $(\AA / \mathrm{wt} \% \mathrm{Nb})$ and relative $(\% / \mathrm{wt} \% \mathrm{Nb})$ units.

\begin{tabular}{|l|c|c|c|}
\hline & a & b & c \\
\hline Q-Uranium & 27 & -1.6 & 24 \\
\hline U-6Nb heating & 120 & -48 & -5 \\
\hline U-6Nb cooling & 54 & -5 & 11 \\
\hline
\end{tabular}

Table 3. Effective single crystal CTE's (units of $10^{-6} / \mathrm{K}$ ) of U-6Nb alloys and pure $\alpha$ uranium [38].

\begin{tabular}{|l|c|c|c|}
\hline Observation & As-quenched & $2 \mathrm{hr} 473 \mathrm{C}$ & $8 \mathrm{hr} 473 \mathrm{C}$ \\
\hline Primary yield point & $110(0.003)$ & $350(0.007)$ & $440(0.009)$ \\
\hline Increase of $(130)$ pole density & $110(0.002)$ & $360(0.004)$ & $450(0.004)$ \\
\hline Secondary yield point & $700(0.06)$ & $730(0.06)$ & $780(0.06)$ \\
\hline Maximum in $(130)$ pole density & $484(0.041)$ & $607(0.042)$ & $653(0.042)$ \\
\hline Minima in $(\overline{1} 30)$ pole density & $285(0.021)$ & $410(0.023)$ & $503(0.023)$ \\
\hline Maximum in $(\overline{1} 30)$ pole density & $770(0.087)$ & $781(0.093)$ & N/A \\
\hline
\end{tabular}

Table 4. Stress (MPa) and strain (in parenthesis) at which various macroscopic and microscopic phenomenon were observed. 
Figure 1. Diffraction patterns from several uranium-niobium alloys after quenching from the high temperature g phase. The upper and lower tick marks in the U6.5 Nb pattern represent the peaks associated with the $\alpha^{\prime \prime}$ and $\gamma_{0}$ phases, respectively.

Figure 2. Lattice parameters of as-quenched uranium-niobium alloys as a function of niobium concentrations (from chemical analysis). Open and closed symbols represent data taken in the 2 banks on the NPD.

Figure 3. Diffraction patterns from as-quenched homogenized U-6Nb material, immediately upon reaching $473 \mathrm{~K}, 36$ hours after reaching $473 \mathrm{~K}$, and after returning to room temperature. The elevated temperature patterns are offset to allow for easier comparisons of patterns collected at like temperatures. Reflections that are relevant to the discussion are indexed.

Figure 4. Diffraction patterns from homogenized $\mathrm{U}-6 \mathrm{Nb}$ in the (a.) as-quenched condition, (b.) immediately after rapid heating to $573 \mathrm{~K}$, (c.) 1 hour after reaching $573 \mathrm{~K}$, and (d.) 35 hours after reaching $573 \mathrm{~K}$.

Figure 5. Evolution of the U-6Nb lattice parameters (a, b, c, g) with time at temperature. The axes on the right indicates the relative change (strain), and all represent $2.5 \%$ full scale. Every 20th data point is represented by a symbol.

Figure 6. Evolution of the lattice strains of the $(\overline{1} 10),(110)$ and $(\overline{1} 11)$ peaks as well as the $(002) /(021)$ doublet (symbols). The lines represent the same strains calculated from the lattice parameters found by Rietveld refinement.

Figure 7. Room temperature diffraction patterns from banded U-6Nb tensile samples in the as-quenched condition as well as after 2 and 8 hours at $473 \mathrm{~K}$.

Figure 8. Stress/strain curves for as-quenched banded U-6Nb as well as material aged 2 and 8 hours at $473 \mathrm{~K}$. The dotted and dashed lines represent the approximate initial and secondary yield points, respectively.

Figure 9. IPF's representing texture evolution of the as-quenched and aged U-6 $\mathrm{Nb}$ at true strains of roughly $0,0.04,0.08$, and 0.12 .

Figure 10. Evolution of the (130) (closed symbols) and (130) (open symbols) pole densities as a function of tensile strain.

Figure 11. Evolution of the (130) (closed symbols) and (130) (open symbols) pole densities as a function of applied stress. The dotted and dashed lines represent the primary and secondary yield points gleaned from Fig. 8.

Figure 12. a.) Transformation strains $\left(\alpha^{\prime \prime}-\gamma^{0}\right)$ calculated from lattice parameters given in [36] when the reverse transformation was driven by deformation. b.) and c.) Strains observed by diffraction when heating homogenized U-6Nb to $473 \mathrm{~K}$ and $373 \mathrm{~K}$, 
Draft Feb. 2016

respectively. Contours range from $-6.5 \%$ to $6.5 \%$ at intervals of $0.5 \%$. The thick like marks 0 .

Figure 13. Observed (solid circles) strain relaxation $(-|\Delta \varepsilon|)$ in a.) lattice parameters and b.) specific single peaks during hold at $473 \mathrm{~K}$ fit with the Feltham equation (solid lines). 


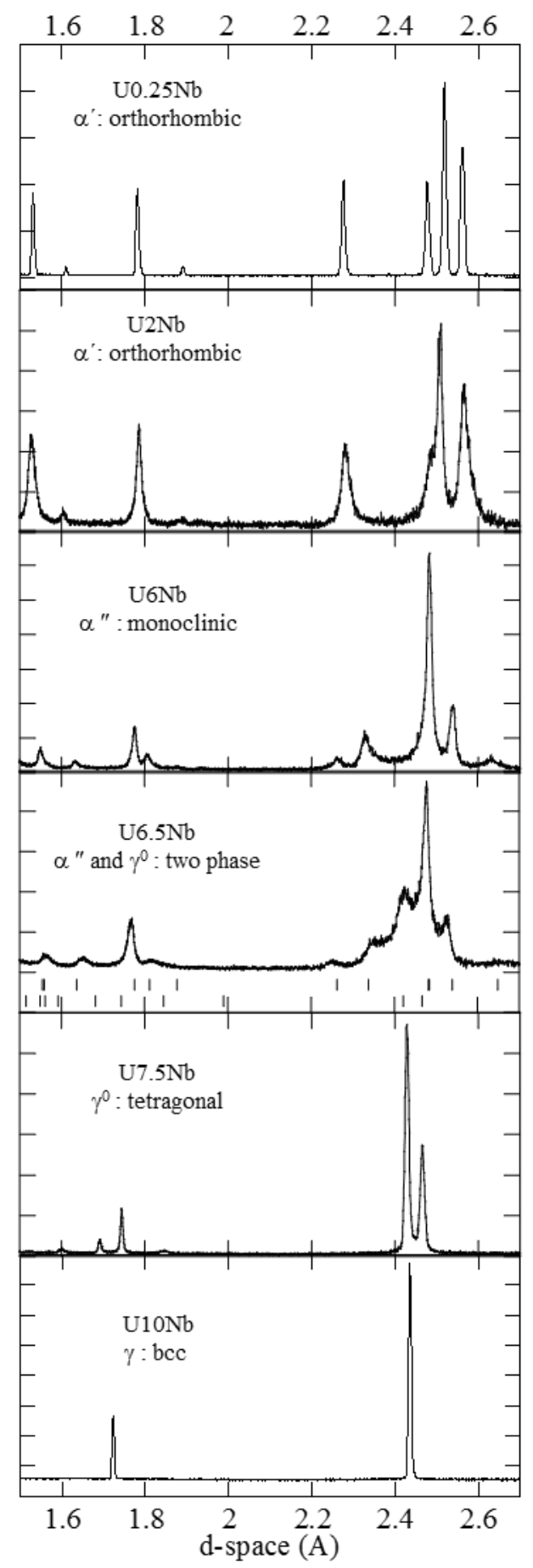

Figure 1. Diffraction patterns from several uranium-niobium alloys after quenching from the high temperature $\gamma$ phase. The upper and lower tick marks in the $\mathrm{U} 6.5 \mathrm{Nb}$ pattern represent the peaks associated with the $\alpha^{\prime \prime}$ and $\gamma^{\circ}$ phases, respectively. 


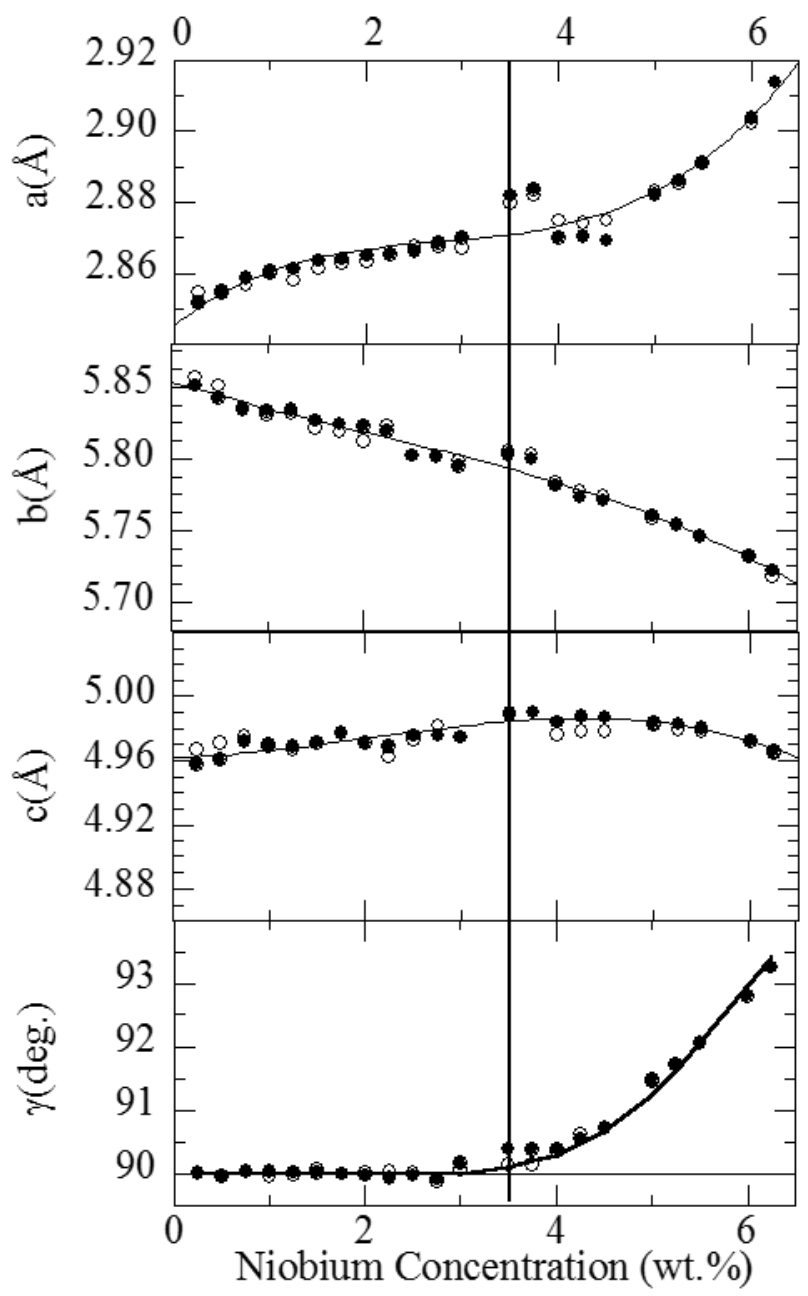

Figure 2. Lattice parameters of as-quenched uranium-niobium alloys as a function of niobium concentrations (from chemical analysis). Open and closed symbols represent data taken in the 2 banks on the NPD. 


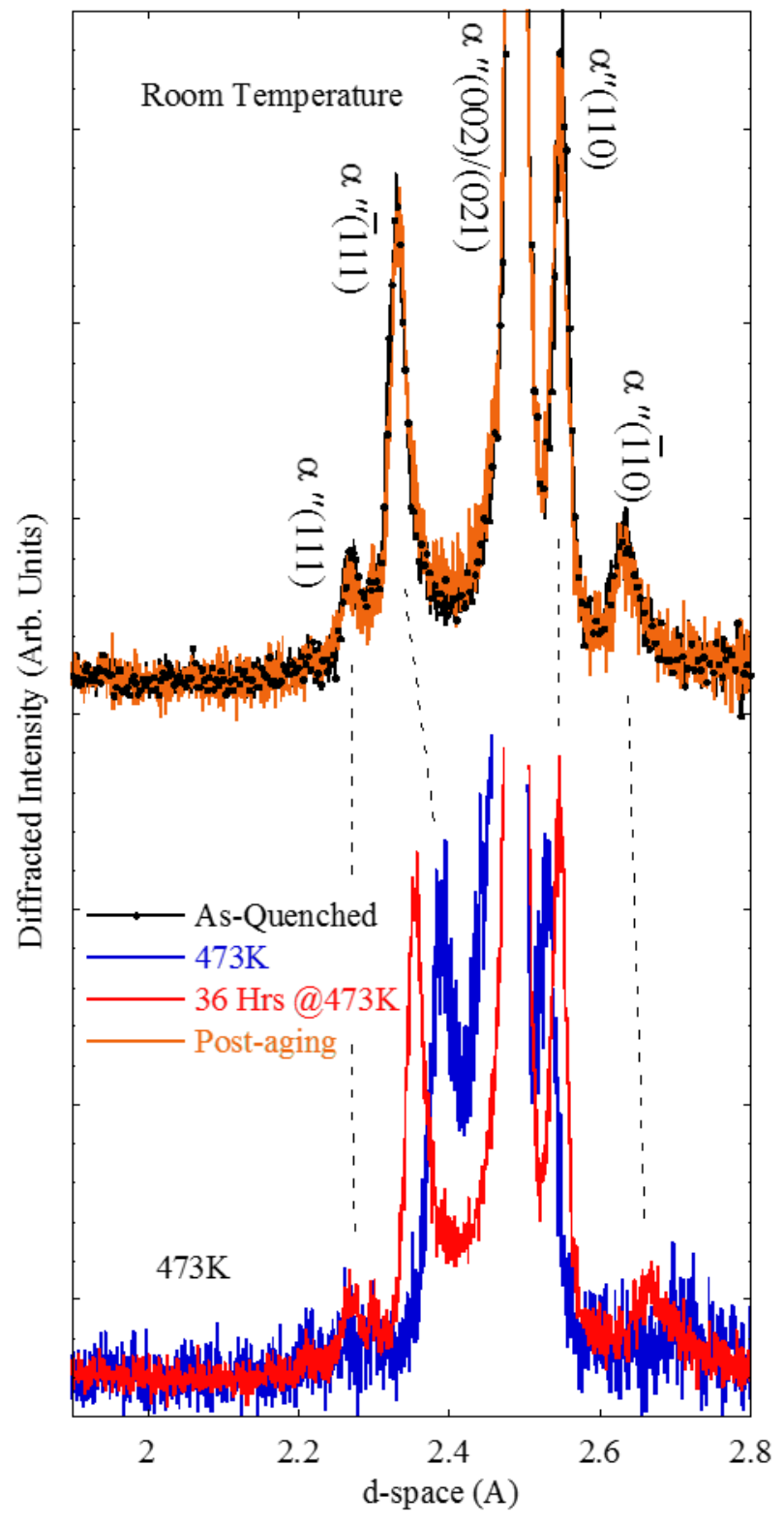

Figure 3. Diffraction patterns from as-quenched $\mathrm{U}-6 \mathrm{Nb}$ material, immediately upon reaching $473 \mathrm{~K}, 36$ hours after reaching $473 \mathrm{~K}$, and after returning to room temperature. The elevated temperature patterns are offset to allow for easier comparisons of patterns collected at like temperatures. Reflections that are relevant to the discussion are indexed. 


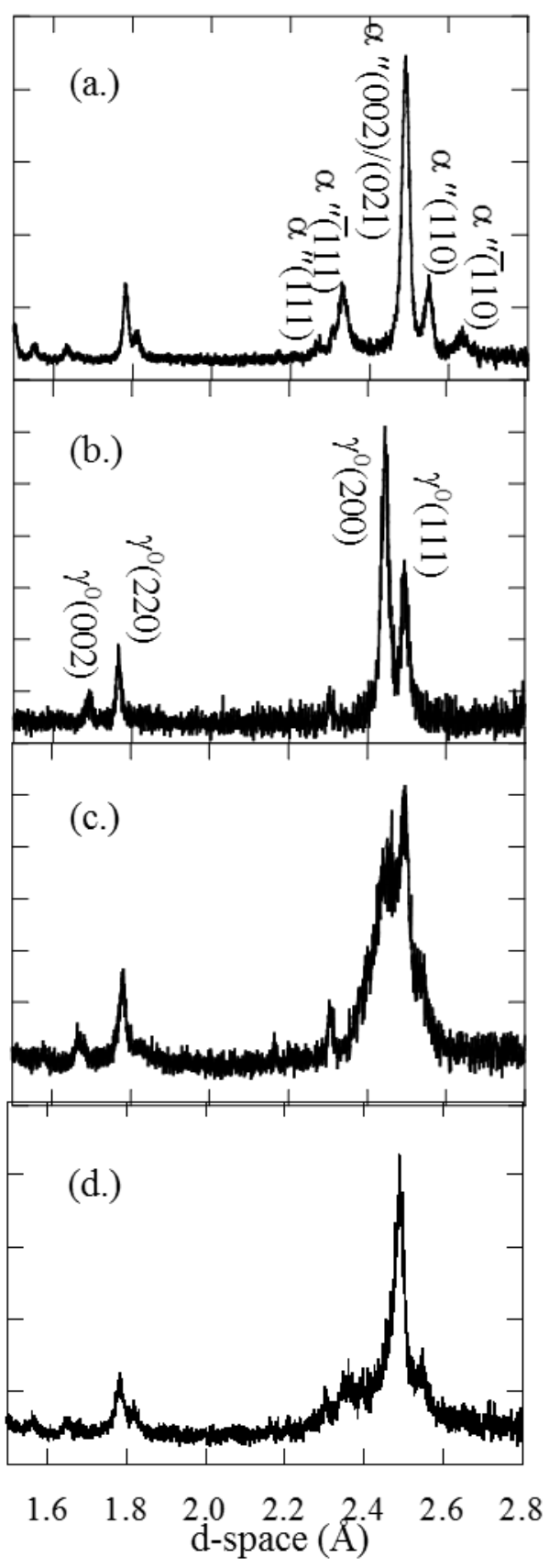

Figure 4. Diffraction patterns from homogenized $\mathrm{U}-6 \mathrm{Nb}$ in the (a.) as-quenched condition, (b.) immediately after rapid heating to $573 \mathrm{~K}$, (c.) 1 hour after reaching $573 \mathrm{~K}$, and (d.) 35 hours after reaching $573 \mathrm{~K}$. 

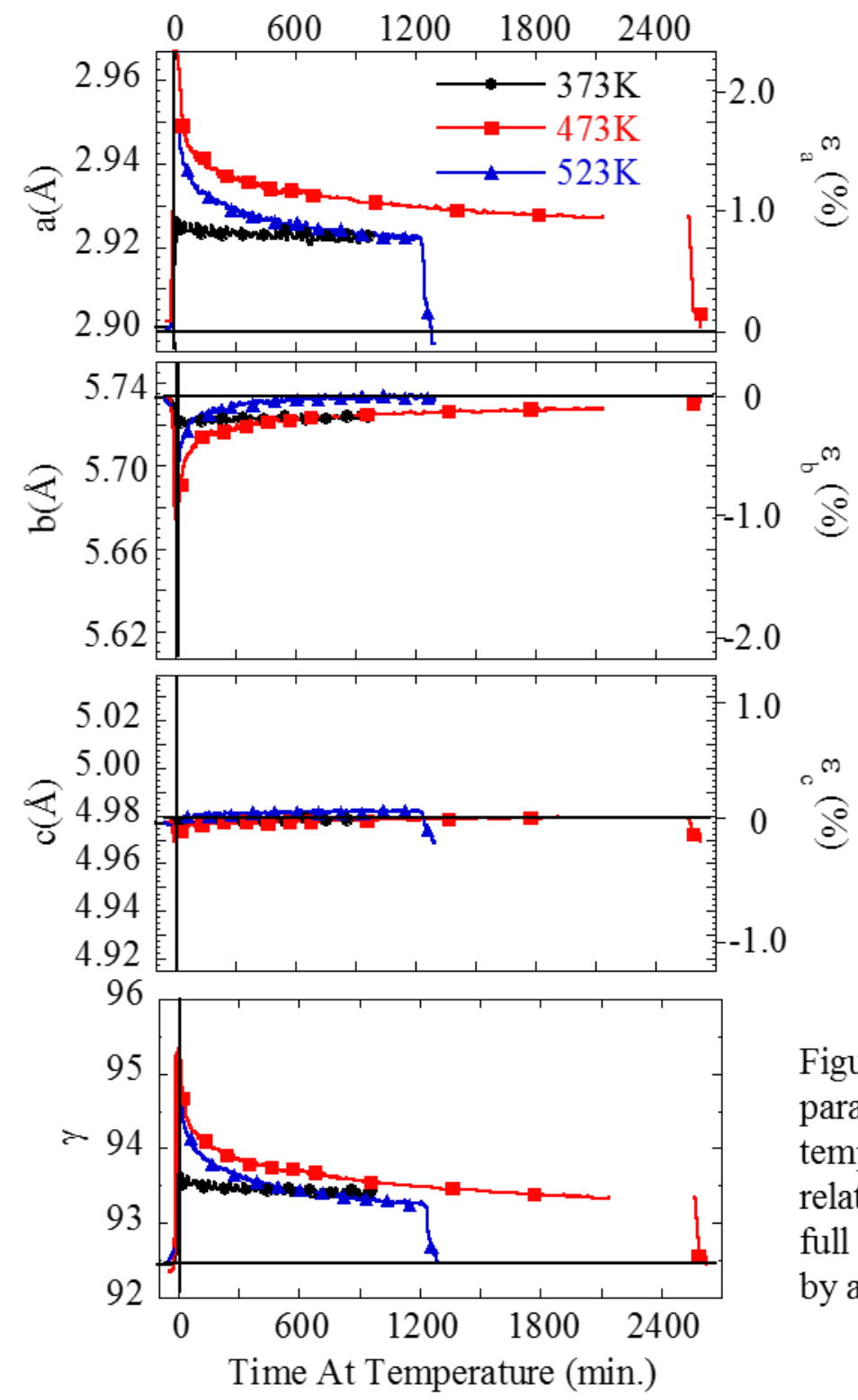

Figure 5. Evolution of the U6 Nb lattice parameters $(\mathbf{a}, \mathbf{b}, \mathbf{c}, \gamma)$ with time at temperature. The axes on the right indicates the relative change (strain), and all represent $2.5 \%$ full scale. Every $20^{\text {th }}$ data point is represented by a symbol. 


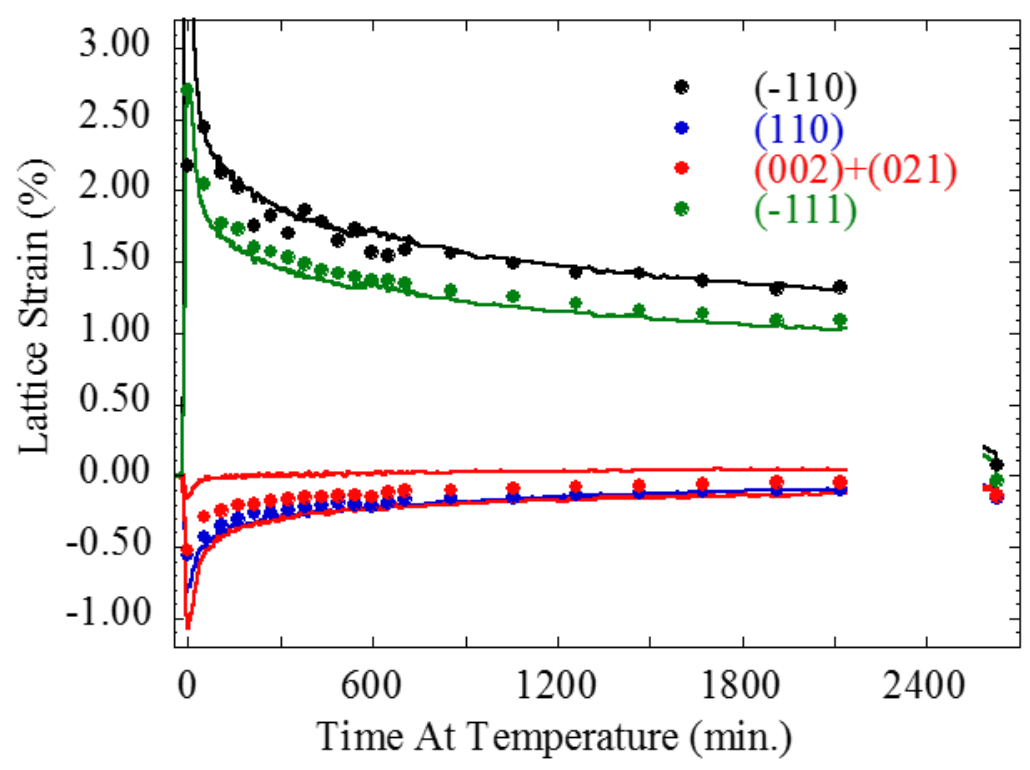

Figure 6. Evolution of the lattice strains of the (-110), (110) and (-111) peaks as well as the (002)/(021) doublet (symbols). The lines represent the same strains calculated from the lattice parameters found by Rietveld refinement. 


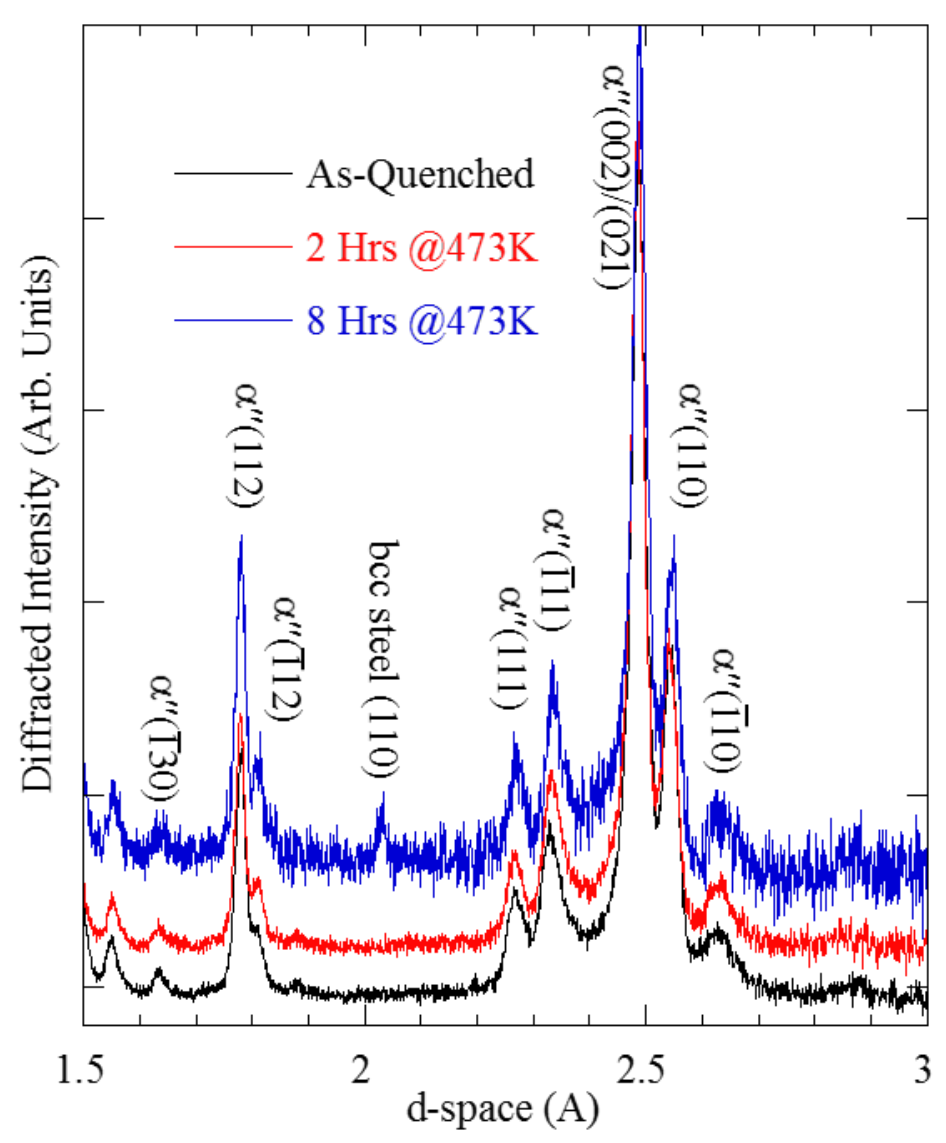

Figure 7. Room temperature diffraction patterns from banded U-6Nb tensile samples in the as-quenched condition as well as after 2 and 8 hours at $473 \mathrm{~K}$. 
Draft Feb. 2016

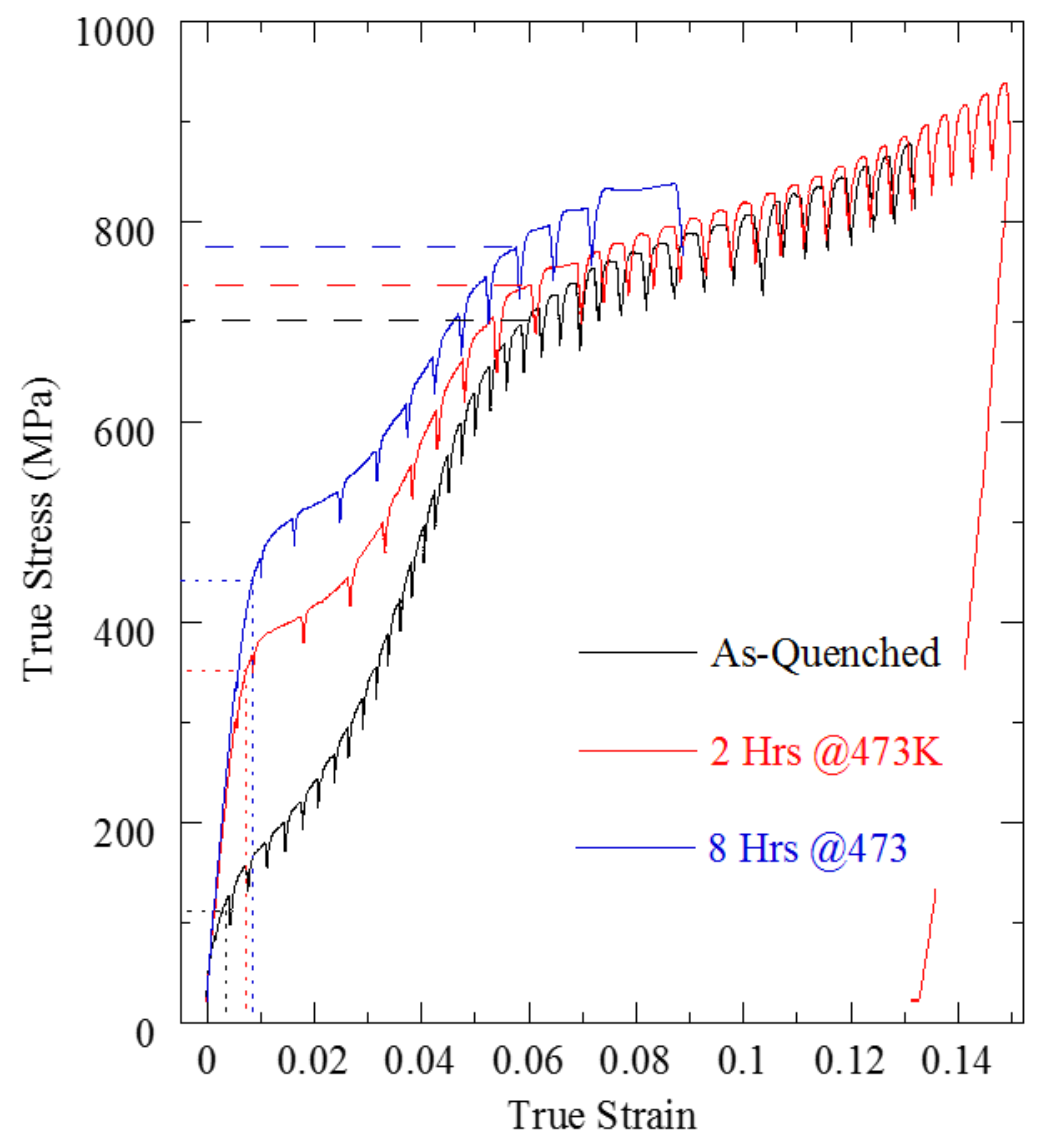

Figure 8. Stress/strain curves for as-quenched banded U-6Nb as well as material aged 2 and 8 hours at $473 \mathrm{~K}$. The dotted and dashed lines represent the approximate initial and secondary yield points, respectively. 
Draft Feb. 2016

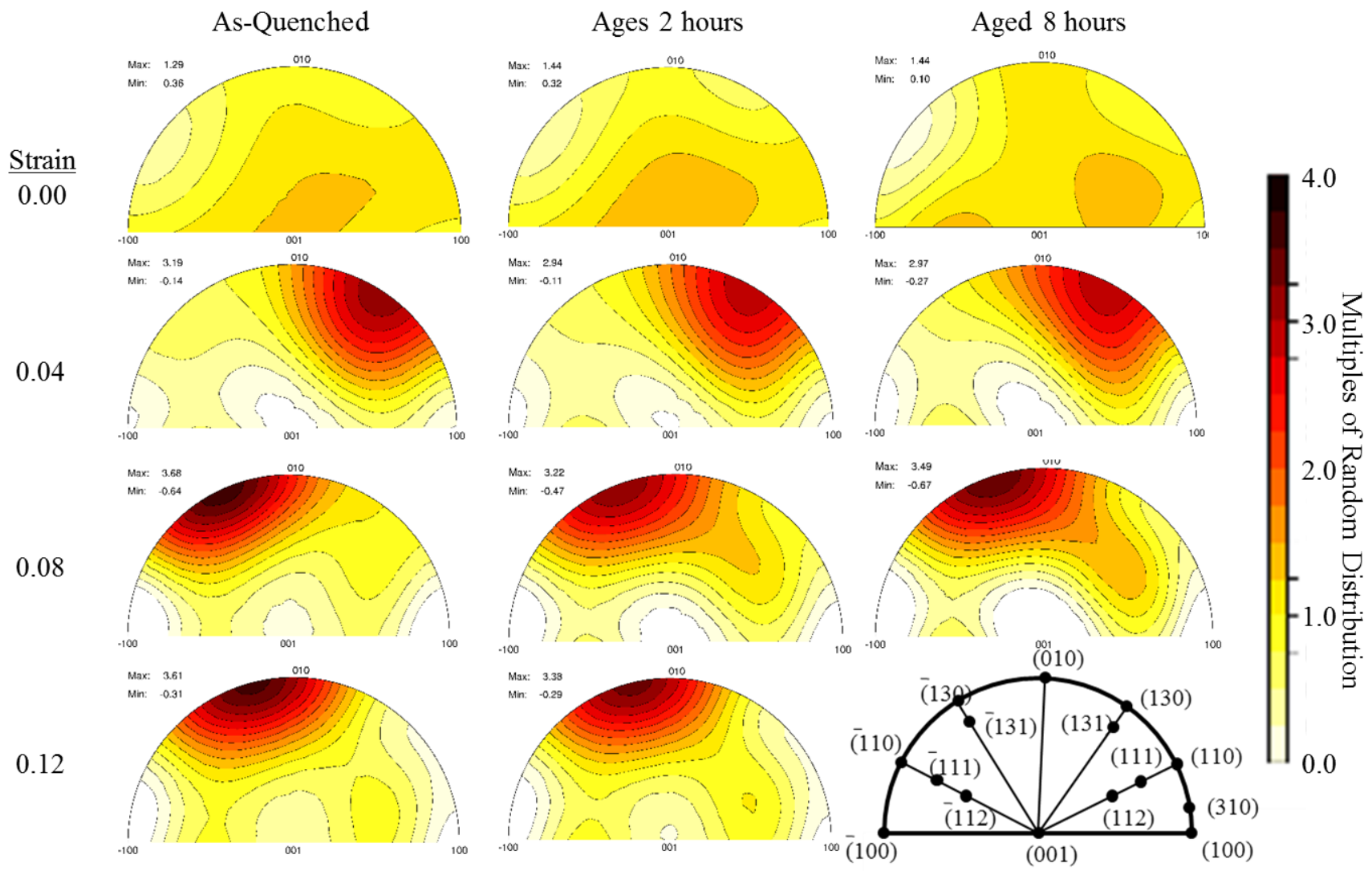

Figure 9. IPF's representing texture evolution of the as-quenched and aged U- $6 \mathrm{Nb}$ at true strains of roughly $0,0.04$, 0.08 , and 0.12 . 
Draft Feb. 2016

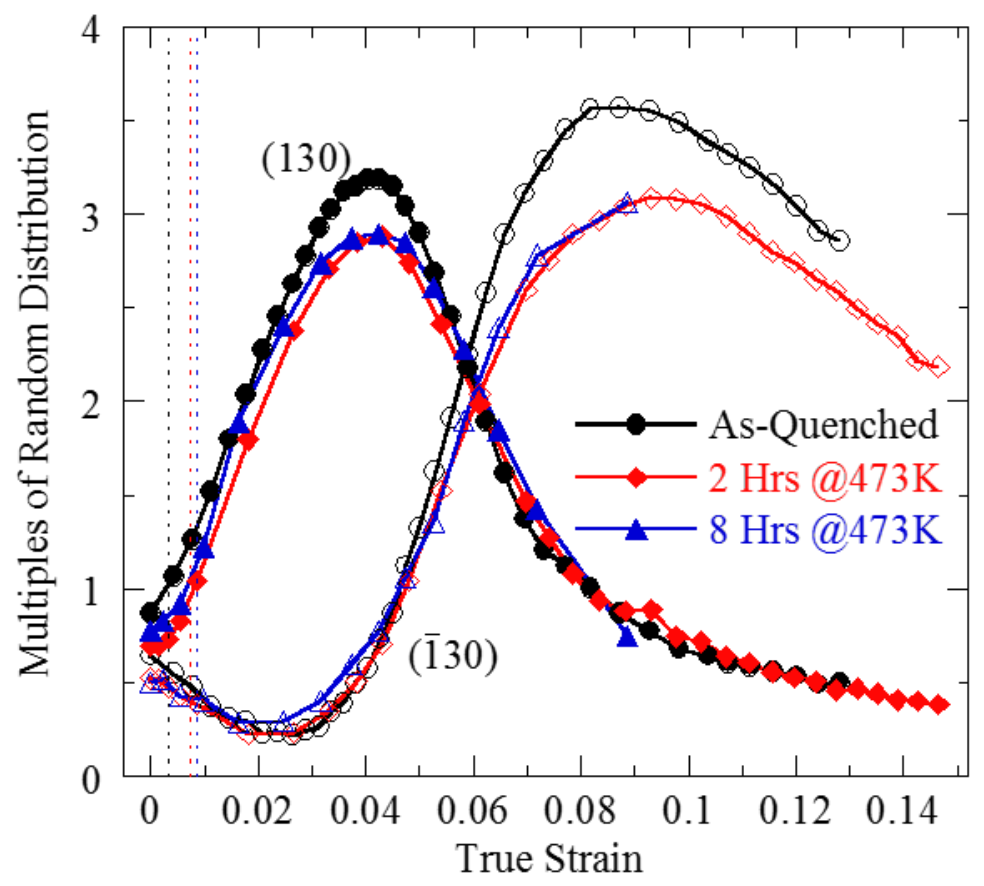

Figure 10. Evolution of the (130) (closed symbols) and (130) (open symbols) pole densities as a function of tensile strain. 


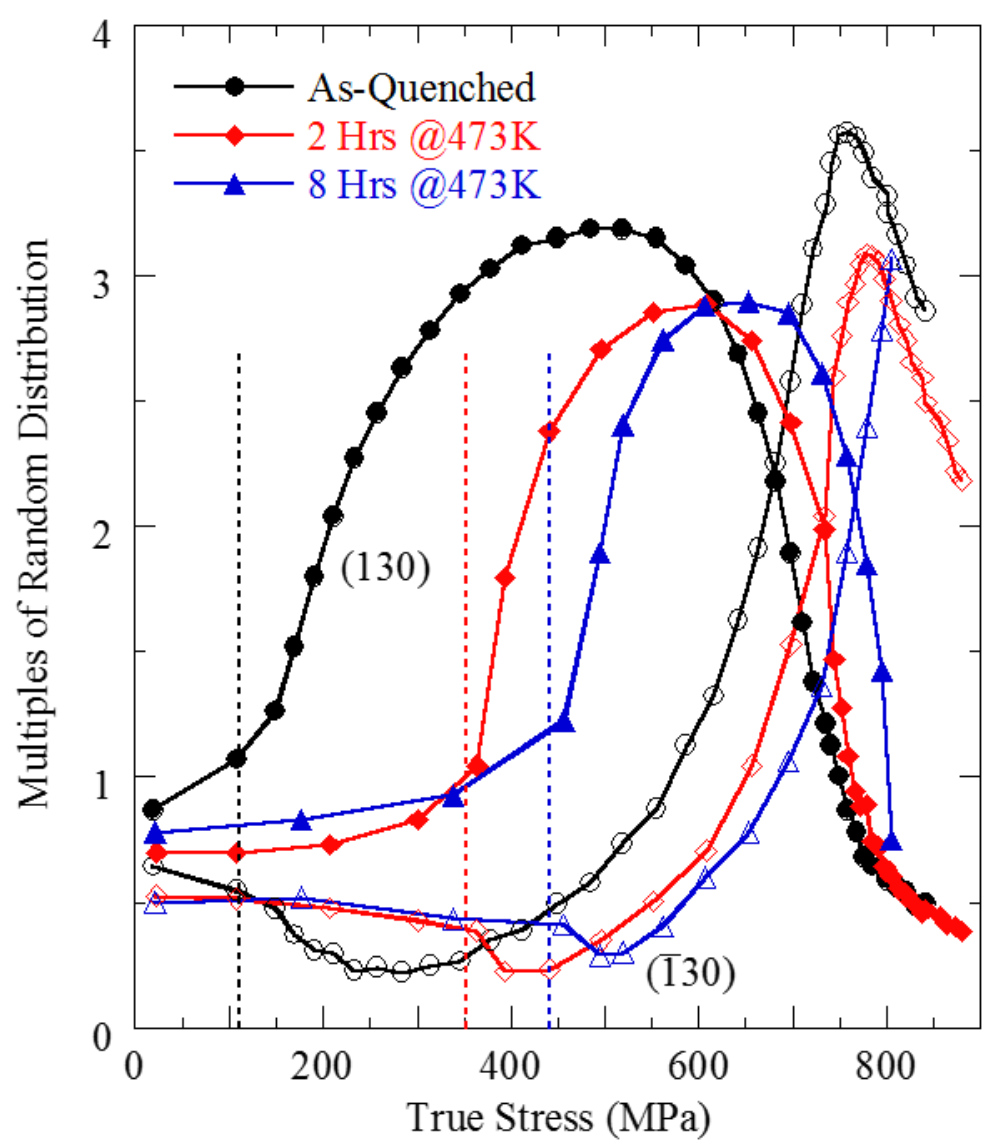

Figure 11. Evolution of the (130) (closed symbols) and (130) (open symbols) pole densities as a function of applied stress. The dotted and dashed lines represent the initial and secondary yield points gleaned from Fig. 8 . 


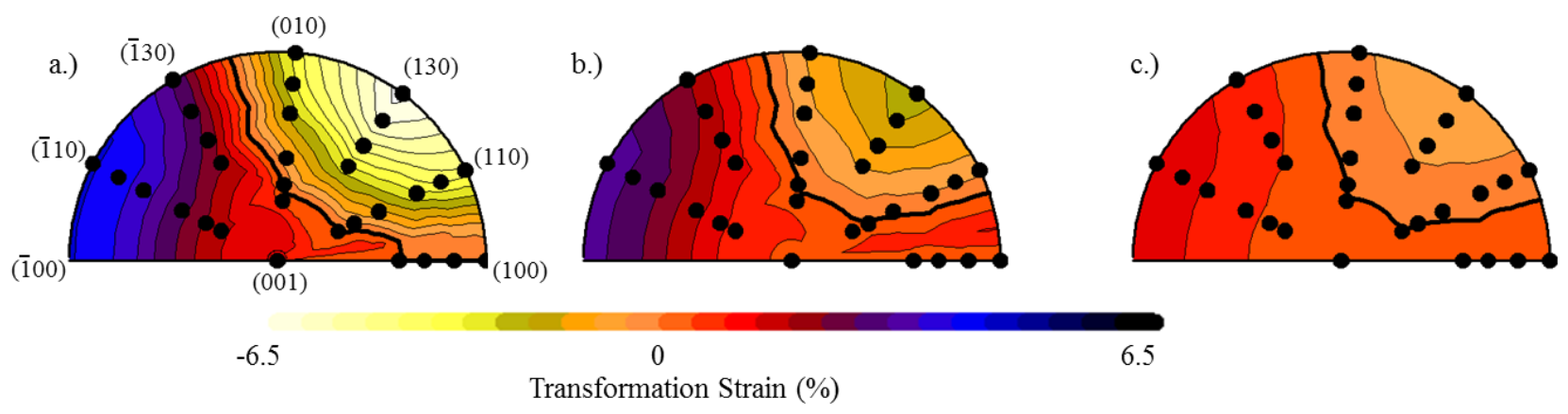

Figure 12 a. Transformation strains $\left(\alpha^{\prime \prime}-\gamma_{0}\right)$ calculated from lattice parameters given in [28] when the reverse transformation was driven by deformation. b.) and c.) Strains observed by diffraction when heating homogenized U$6 \mathrm{Nb}$ to $473 \mathrm{~K}$ and $373 \mathrm{~K}$, respectively. Contours range from $-6.5 \%$ to $6.5 \%$ at intervals of $0.5 \%$. The thick like marks 0 . 

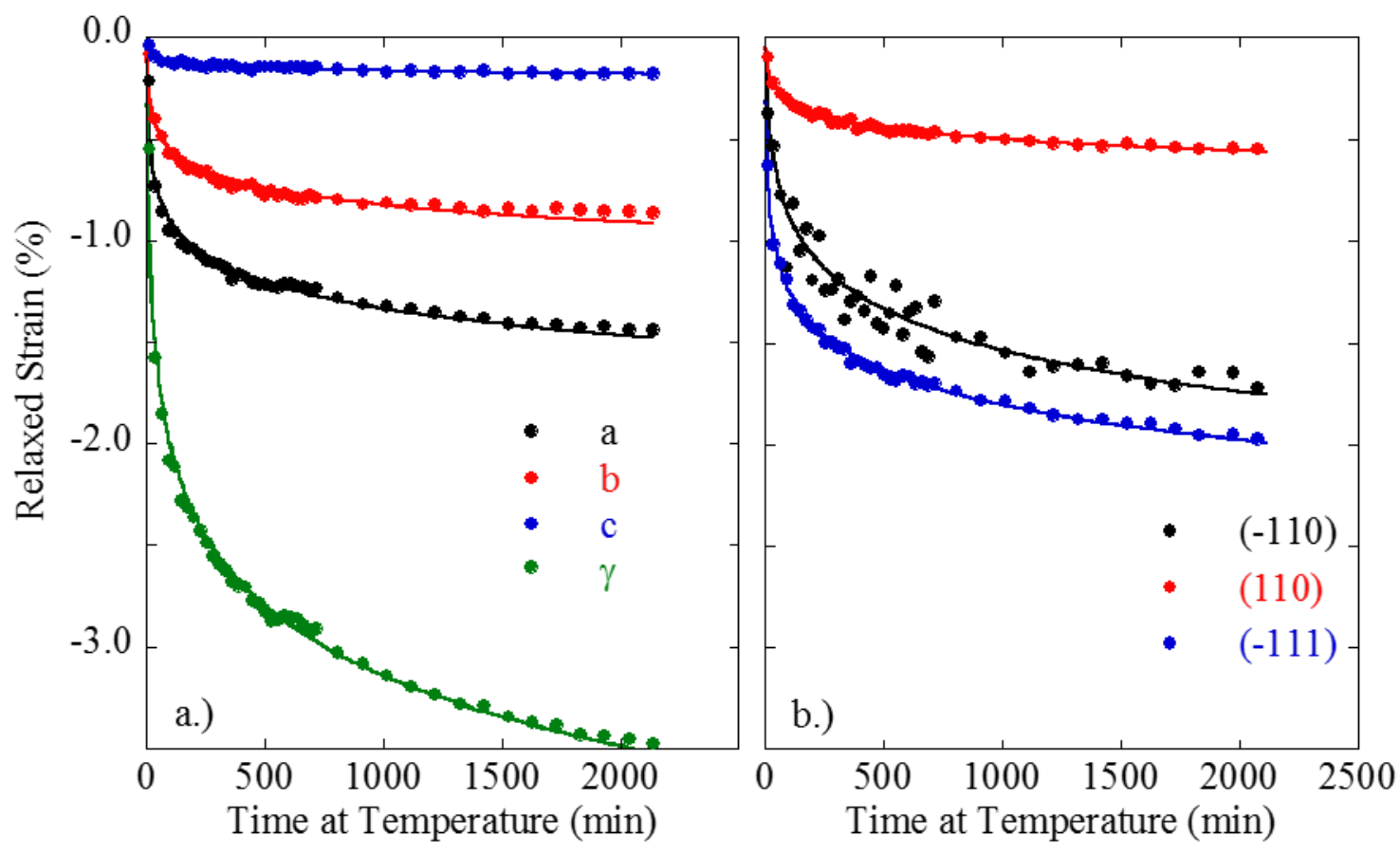

Figure 13. Observed (solid circles) strain relaxation $(-|\Delta \varepsilon|)$ in (a.) lattice parameters and (b.) specific single peaks during hold at $473 \mathrm{~K}$ fit with the Feltham equation (solid lines). 
Draft Feb. 2016

References

[1] T.B. Massalski, J.L. Murray, L.H. Bennett, H. Baker, Binary Alloy Phase Diagrams, ASM International, Materials Park, Oh, 1990.

[2] B.W. Howlett, J Nuc Matl 1961(4), 1969.

[3] K. Tangri, G.I. Williams, J Nuc Matl 41961 226-233.

[4] M. Anagnostidis, M. Colombie, H. Monti, J Nuc Matl 26 1963 67-76.

[5] Y. Takahashi, M. Yamawaki, K. Yamamoto, J Nuc Matl 154(\#1), 1988 141-144.

[6] E. Kahana, M. Talianker, A. Landau, J Nuc Matl 2461997 144-149.

[7] J.G. Speer, D.V. Edmonds, Acta Met 36(4), 1988 1015-1033.

[8] K.H. Eckelmeyer, A.D. Romig, L.J. Weirick, Met. Trans. A 15(\#7), 1984 1319-1330.

[9] R.A. Vandermeer, Acta Met 28(\#3), 1980 383-393.

[10] R.J. Jackson, Reversible Martensitic Transformations Between Transition Phases of Uranium-Base Niobium Alloys, Rocky Flats Division, The Dow Chemical Company, Golden Colorado,RFP-1535, 1970.

[11] K. Tangri, K. Chaudhuri, J Nuc Matl 15(4), 1965 278-287.

[12] H.L. Yakel, A Review of X-Ray Diffraction Studies in Uranium Alloys, in: J.J. Burke, D.A. Colling, A.E. Gorum, J. Greenspan (Eds.) Physical Metallugy of Uranium Alloys :Third Army Materials Technology Confernece, Brook Hill Publishing Company, Vail, Colorado, 1974, pp. 259-307.

[13] J. Lehmann, R.F. Hills, J Nuc Matl 21960 261-268.

[14] R.E. Hackenberg, D.W. Brown, A.J. Clarke, L.B. Dauelsberg, R.D. Field, W.L. Hults, A.M. Kelly, M.F. Lopez, D.F. Teter, D.J. Thoma, T.J. Tucker, C.J. Vigil, H.M. Volz, U-Nb Aging Final Report, Los Alamos National Lab, Los Alamos, NM,LA-14327, 2007.

[15] R.A. Vandermeer, J.C. Ogle, W.G. Northcutt, Met. Trans. A 12(\#5), 1981 733-741.

[16] R.A. Vandermeer, J.C. Ogle, W.B. Snyder, Scripta Met 12(\#3), 1978 243-248.

[17] D.W. Brown, M.A.M. Bourke, P.S. Dunn, R.D. Field, M.G. Stout, D.J. Thoma, Met Trans A 32(9), $20012219-2228$.

[18] C.N. Tupper, D.W. Brown, R.D. Field, T.A. Sisneros, B. Clausen, Met Trans A 43A(2), 2012520 530 .

[19] R.D. Field, D.W. Brown, D.J. Thoma, Phil. Mag. 85(13), 2005 1441-57.

[20] R.D. Field, D.J. Thoma, P.S. Dunn, D.W. Brown, C.M. Cady, Phil. Mag. A 81(7), 2001 1691-1724.

[21] C. Damato, F.S. Saraceno, T.B. Wilson, J Nuc Matl 12(3), 1964 291-304.

[22] R.J. Jackson, D.V. Miley, ASM -- Transactions 61(2), 1968 336-343. 
Draft Feb. 2016

[23] A.J. Clarke, R.D. Field, R.E. Hackenberg, D.J. Thoma, D.W. Brown, D.F. Teter, M.K. Miller, K.F. Russell, D.V. Edmonds, G. Beverini, J Nuc Matl 393(2), 2009 282-291.

[24] B. Djuric, J Nuc Matl 44(2), 1972 207-\&.

[25] R.E. Hackenberg, H.M. Volz, P.A. Papin, A.M. Kelly, R.T. Forsyth, T.J. Tucker, K.D. Clarke, Diffusion and Defect Data Part B (Solid State Phenomena) 172-174 2011 555-60.

[26] L. Hsiung, L., Low-Temperature Aging Mechaninsms in U-6.0wt\% Nb, Lawrence Livermore National Laboratory, Livermore, Ca,UCLR-TR-208589, 2004.

[27] G. Beverini, D.V. Edmonds, Journal De Physique 50(C8), 1989 C8429-C8434.

[28] G. Beverini, Phase Transformations in Binary Uranium Alloys, University of Oxford, Oxford, UK, 1991.

[29] R.D. Field, D.J. Thoma, J Nuc Matl 436(1-3), 2013 105-117.

[30] M.A.M. Bourke, J.A. Goldstone, T.M. Holden, Residual Stress Measurement Using the Pulsed Neutron Source at LANSCE, in: M.T. Hutchings, A.D. Krawitz (Eds.), Measurement of Residual and Applied Stress Using Neutron Diffraction, Kluwer Academic Publishers, The Netherlands, 1992, pp. 369382.

[31] M.A.M. Bourke, D.C. Dunand, E. Ustundag, App. Phys. A A74 2002 S1707-S1709.

[32] R.B. Vondreele, J.D. Jorgensen, C.G. Windsor, J. App. Crys. 15 1982 581-589.

[33] D.W. Brown, M.A.M. Bourke, R.D. Field, W.L. Hults, D.F. Teter, D.J. Thoma, S.C. Vogel, Mat Sci Eng A 421(1-2), 2006 15-21.

[34] P.W. Stephens, J. App. Crys. 321999 281-289.

[35] R.B. Von Dreele, J. App. Crys. 301997 517-525.

[36] D.A. Carpenter, R.A. Vandermeer, Journal De Physique 43(\#C-4), 1982 395-400.

[37] J.M. Fackelmann, A.A. Bauer, M. D.P., Literature Survey on Dilute Urnaium Alloys, Battelle Memorial Institute, Columbus, Ohio,BMI-X-10264, 1969.

[38] G.H. Lander, E.S. Fisher, S.D. Bader, Advances in Physics 43(\#1), 1994 1-111.

[39] A.J. Clarke, R.D. Field, R.J. McCabe, C.M. Cady, R.E. Hackenberg, D.J. Thoma, Acta Mat 562008 2638-2648.

[40] J.A. Monroe, D. Gehring, I. Karaman, R. Arroyave, D.W. Brown, B. Clausen, Acta Mat 1022016 333-341.

[41] P.A. Turner, C.N. Tome, J. Mech. Phys. Solids 41(7), 1993 1191-1211.

[42] B. Clausen, T. Lorentzen, T. Leffers, Acta Mat 46(\#9), 1998 3087-3098.

[43] Trouton, A.O. Rankine, Phil. Mag. 8(43-48), 1904 538-556.

[44] P. Feltham, Journal of the Institute of Metals 89(6), 1961 210-214. 
Draft Feb. 2016

[45] B. Jakobsen, H.F. Poulsen, U. Lienert, J. Bernier, C. Gundlach, W. Pantleon, Phys. Stat. Solid A 206(1), 2009 21-30.

[46] K.K. Ray, A.K. Mallik, Mat Sci Eng 59(1), 1983 59-67.

[47] J.P. Hirth, R.C. Pond, Acta Mat 44(12), 1996 4749-4763.

[48] R.C. Pond, S. Celotto, J.P. Hirth, Acta Mat 51(18), 2003 5385-5398.

[49] P. Feltham, Phil. Mag. 6(62), 1961 259-270.

[50] P. Feltham, Phil. Mag. 6(67), 1961 847-850. 